\title{
Wind variability and Earth's rotation as drivers of transport in a deep, elongated subalpine lake: The case of Lake Garda
}

\author{
Marina AMADORI,${ }^{1 *}$ Sebastiano PICCOLROAZ,${ }^{2}$ Lorenzo GIOVANNINI, ${ }^{1}$ Dino ZARDI, ${ }^{1,3}$ Marco TOFFOLON ${ }^{1}$ \\ ${ }^{1}$ Department of Civil, Environmental and Mechanical Engineering (DICAM), University of Trento, Italy; ${ }^{2}$ Institute for Marine and \\ Atmospheric Research (IMAU), Department of Physics, Utrecht University, The Netherlands; ${ }^{3}$ Center Agriculture Food Environment \\ (C3A), University of Trento, Italy \\ *Corresponding author: marina.amadori@unitn.it
}

\begin{abstract}
The effects of wind forcing and Earth's rotation on the transport processes in Lake Garda (Italy) are investigated for the first time under different thermal stratification conditions and typical diurnal wind cycles. Numerical simulations are performed by means of a modeling chain composed of a meteorological (WRF) and a hydrodynamic (Delft3D) model. Transport processes are studied through the combined analysis of the residual (time averaged) flow field and the trajectories of Lagrangian particles. Results show that strong currents develop in winter under the forcing of synoptic northerly Föhn winds, especially in the elongated northern region, where winds are channeled by the steep orography. Significant water volumes are displaced laterally by Ekman transport, producing intense downwelling and upwelling along the steep shores. Instead summer patterns are controlled by the diurnal cycle of local breezes, alternately blowing along the main axis of the lake. The resulting circulation reveals counterclockwise gyres in the northern part, driven by the alternating wind direction and affected by Coriolis force. The analysis suggests that complex circulations can develop in lakes with relatively simple geometries, like the narrow trunk region of Lake Garda, where the effect of Earth's rotation unexpectedly influences the transport patterns.
\end{abstract}

Key words: Lake circulation, atmosphere-lake numerical modeling; deep lakes; transport processes.

Received: April 2018. Accepted: July 2018.

\section{INTRODUCTION}

Water motions in lakes are predominantly driven by the action of wind forcing on the water surface. In particular, the wind action produces two main effects: triggering both surface and internal waves, as well as driving lake circulation. While the latter process was a common subject in early pioneering contributions (see the reviews in Heaps, 1984; Hutter et al., 2011), in the last decades the scientific literature has mostly focused on the motions produced by internal waves in stratified conditions (Hodges et al., 2000; Umlauf and Lemmin, 2005).

From a modeling point of view, the interaction between atmosphere and lake dynamics has been the subject of increasingly numerous investigations ( Crosman and Horel, 2010), thanks to the advances in computational power (Notaro et al., 2013; Zhong et al., 2016; Huziy and Sushama, 2017). Numerical models including different features and complexity have been developed to simulate lake physical processes under different meteorological constraints, ranging from simple, decoupled onedimensional lake models ( Goudsmit et al., 2002; Perroud et al., 2009; Piccolroaz and Toffolon, 2013), to more complex, two-way coupled three-dimensional models (Song et al., 2004; Leon et al., 2007; Xue et al., 2016), with a wide range of intermediate examples (Schwab et al., 1989; Hostetler et al., 1993; Goyette and Perroud, 2012; Schimmelpfenning et al., 2012).

In principle, a two-way coupling approach is needed to achieve a detailed description of lake-atmosphere interaction. However, lacustrine dynamics under atmospheric forcing are routinely described by one-way coupled models (Kelley et al., 1993; Pan et al., 2002; Valerio et al., 2017), or stand-alone uncoupled hydrodynamic models, driven by realistic meteorological conditions through spatial interpolation of observations (Laval et al., 2003). Oversimplified atmospheric forcing, such as horizontally uniform and/or stationary wind fields, can instead produce large inaccuracies (Strub and Powell, 1986), resulting in modeled lake circulations poorly representative of real conditions.

However, wind is not the only factor controlling lake hydrodynamics. Stratification conditions and the effect of Earth's rotation chiefly concur to affect residual circulation (here defined as the time-averaged velocity field), turbulence (described by increasingly complex approaches, 
e.g., Large Eddy Simulations (Santo et al., 2017)), mixing dynamics (e.g., deep mixing processes, upwelling/ downwelling regions), and the fate of nutrients, pollutants and particulate matter. A deep understanding of how these main drivers interact is a key step for any comprehensive description of the physical behavior of a lake and for supporting optimal lake management. This may be often challenged by the increasing complexity of two factors: the shape and the bathymetry of the lake, whereby deep and narrow regions react differently than wide and shallow ones, and the surrounding orography, which controls the spatial and temporal variations of the wind field (Rueda et al., 2005). In this respect, Lake Garda (Italy) is an extraordinary example of both aspects and represents a relevant, yet almost entirely unexplored, case study.

The present work takes a first step towards the understanding of hydrodynamics of Lake Garda under realistic wind and stratification conditions. Numerical experiments were performed by means of the threedimensional hydrodynamic model Delft3D to quantify the transport processes resulting from wind field and thermal conditions typical of the summer and winter seasons. Currently, no hydrodynamic measurements are available in Lake Garda, thus effectively precluding proper model calibration and validation. Being aware of this limit, which cannot be overcome in a short time, our intent here is not to set up a predictive tool for Lake Garda, but to achieve a first-order description of the possible hydrodynamic behavior of the lake under typical seasonal conditions. To this aim, model experiments were designed as single-day simulations where stratification conditions are specified on the basis of measured temperature profiles, while wind fields are obtained from atmospheric model (WRF) runs specifically set up for the study region (Giovannini et al., 2014b).

The underlying question concerns the understanding of how circulation and transport processes in elongated and deep Alpine lakes are controlled by thermal stratification and by the temporal and spatial variability of the wind forcing, including the non-negligible effect of the Earth's rotation. Additionally, modeling exercises as the one presented here are effective preparatory steps, providing useful insights and directions to plan field activities in ungauged or scarcely monitored lakes.

\section{METHODS}

\section{Case study and available data set}

Lake Garda is one of the most important subalpine lakes in Europe and the largest in Italy as to surface area and volume. It is located in northern Italy (Fig. 1a) at $45^{\circ} 40^{\prime} \mathrm{N}$ mean latitude and $10^{\circ} 40^{\prime} \mathrm{E}$ mean longitude, and the average free surface level is at $65 \mathrm{~m}$ above sea level.
The lake is a renowned destination and attracts over 20 million tourists every year. The basin surface area is 367 $\mathrm{km}^{2}$, with a maximum length of $52 \mathrm{~km}$ from the northwest (Riva del Garda) to the south-east (Peschiera del Garda), and a maximum width of $18 \mathrm{~km}$ in the southern part of the lake, for a total perimeter of $162 \mathrm{~km}$. The shape and the bathymetry of the lake are strongly inhomogeneous: the northern part is elongated, narrow and deep, with steep shores and a maximum depth of 346 $\mathrm{m}$, and is surrounded by a complex topography with mountains up to $2000 \mathrm{~m}$ above sea level belonging to the Prealps falling into the lake. The southern part is shallower, approximately rounded and about $15 \mathrm{~km}$ wide, with maximum depths around $100 \mathrm{~m}$. A submerged ridge, running eastward from the peninsula of Sirmione to Punta San Vigilio, divides the lake into a western deep and elongated sub-basin, covering most of the lake area, and an eastern one, shallower and significantly smaller. The only available bathymetric survey was performed in 1966 by the Italian Military Geographic Institute (IGM). Lake Garda has one major tributary, the Sarca river, entering the lake near the town of Torbole on the northern shore, and one outflow, the Mincio river, close to the town of Peschiera in the southernmost part.

During the warm season and on sunny days, dailyperiodic thermally-driven atmospheric circulations develop over Lake Garda especially in the northern part: the 'Peler' wind blows from the north at night and until late morning, when it is replaced by the 'Ora del Garda' wind, a lake breeze blowing from the south until sunset (Defant, 1909; Laiti et al., 2013a, 2013b; Laiti et al., 2014; Giovannini et al., 2015). During winter, winds are usually weaker than in the warm season, with the exception of some cases of strong synoptic northerly winds, mainly related to Föhn episodes.

The lake has been monitored since the early ' 90 . Regular samplings of physicochemical and biological parameters have been collected for water quality assessment. Measurements are compliant to the Water Framework Directive 2000/60/EC after its adoption (e.g., dissolved oxygen, $\mathrm{pH}$, conductivity, chlorophyll-a, etc.). To date, hydrodynamics measurements (e.g., velocity fields) have never been made, while turbulence related quantities have been collected since early 2017 (Toffolon et al., 2017) and will be available soon.

\section{Atmospheric model}

Meteorological conditions were simulated using the mesoscale meteorological model WRF (Skamarock et al., 2008), which is largely used for both research and operational applications ranging from the synoptic scale to the microscale. Recently, WRF was successfully used to reproduce the development of thermally-driven circulations in the lake area, chiefly the 'Ora del Garda' 


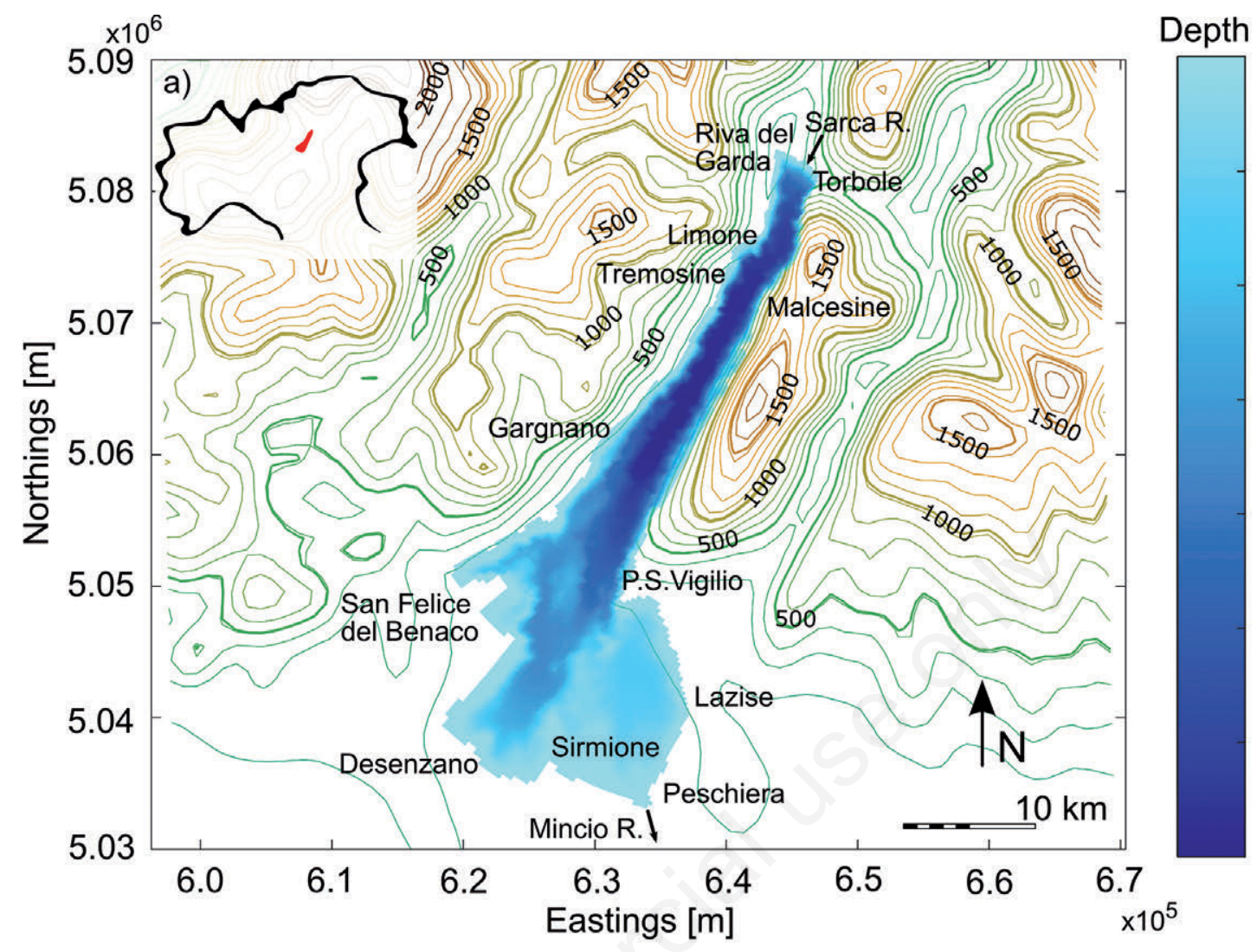

Depth $[\mathrm{m}]$

50

100

150

200

250

300

350
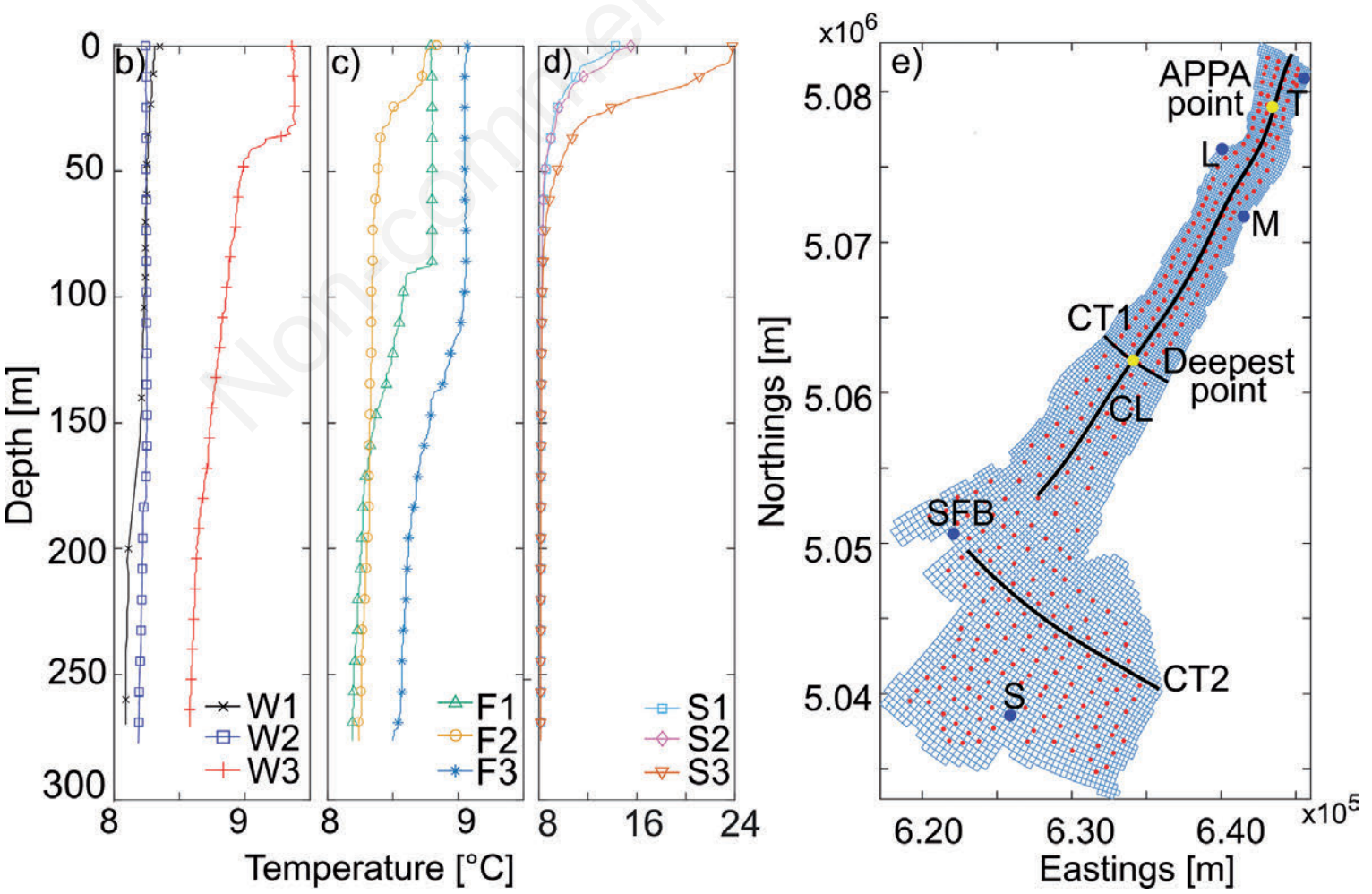

Fig. 1. a) Geographic location of Lake Garda in northern Italy (inset), topography of the region surrounding the lake and bathymetry adopted in the models. Temperature profiles used in winter $(b, c)$ and summer $(d)$ numerical simulations (measured at APPA monitoring point). e) Computational grid, relevant cross sections (CL, CT1, CT2), particle-tracking release points (red dots), geographically relevant points (blue dots). 
(Giovannini et al., 2014a), and to produce a wind atlas for Trentino, including the area of Lake Garda, based on 10year long simulations (from 2003-2014, see Giovannini et al., 2014b). Details about the implementation of the model are provided in the Supplementary Material.

Three different one-day periods were simulated in summer and six in winter, for a total of nine different scenarios. The use of more than one scenario per season was preferred to get more robust results and a better description of the differences between the two seasons. In particular, six wintertime scenarios were chosen to study two different wind patterns occurring in Lake Garda in this season: three of them (F1, F2 and F3) are representative of synoptic Föhn winds blowing from north-east, whereas weak breezes develop in the other three (W1, W2 and W3). In Fig. 2 the temporal evolution (a) and the spatial distribution (b) of the Föhn wind is shown for F3. Analogously, three summertime scenarios (S1, S2, and S3) were selected on the basis of the development of the typical thermally-driven 'Peler' and 'Ora del Garda' breezes over the lake: their diurnal cycle (a) and spatial pattern (c and d) are presented in Fig. 2 for the case of S3. All wind diurnal cycles are shown in the Supplementary Material, while the dates selected for the wind conditions and the respective mean wind speeds are reported in Tab. 1.

\section{Hydrodynamic model}

Lake hydrodynamics were simulated using the opensource modeling suite Delft3D (Lesser et al., 2004), which is increasingly applied for lake studies (Razmi et al., 2013; Wahl and Peeters, 2014; Razmi et al., 2017). The Delft3D-Flow module solves the Reynolds Averaged Navier-Stokes equations (RANS) for an incompressible fluid with the Boussinesq approximation. Turbulence is described by a $k-\varepsilon$ model, providing the vertical eddy diffusivity and viscosity, while the values of the horizontal turbulence parameters are prescribed. The main parameter settings of the model runs are summarized in the Supplementary Material.

A staggered orthogonal curvilinear grid of $64 \times 224$ cells was adopted with a non-uniform mesh (Fig. 1e), and cell size varying from $100 \mathrm{~m}$ in the northern narrow part to $400 \mathrm{~m}$ in the southern wider part. Vertical discretization was based on horizontal layers (Z-model), for a total number of 61 layers with increasing thickness from the top layer $(1 \mathrm{~m})$ to the bottom layer $(50 \mathrm{~m})$. Lake bathymetry was obtained from the IGM map (Fig. 1a). Three representative cross-sections were considered in the analysis (Fig. 1e), namely the longitudinal cross-section (CL) along the narrow and elongated trunk region, and two transverse cross sections, one at the center of the northern elongated trunk (CT1) and one in the southern basin from Lazise to San Felice del Benaco (CT2).

The contribution of inflows and outflows was neglected because of the long water renewal time in Lake Garda, estimated by (Irsa, 1974) in 27 years. Similarly, all additional parameters that were not crucial in the analysis of seasonal scenarios were discarded. For this reason, the exchange of heat through the lake surface is not computed, and the lake is modeled as an adiabatic system, where wind stress is the only driver. Space and time varying fields of wind speed components at $10 \mathrm{~m}$ above ground level and surface atmospheric pressure are provided by the WRF simulations.

A total of nine hydrodynamic simulations were performed, one for each one-day period for which the wind field was available. Hydrodynamic simulations were run for a four-day cycle replicating the same daily atmospheric forcing. Simulation time was set at UTC +0 in accordance with atmospheric simulations. Initial conditions were set as water at rest and perfectly horizontal water level; the temperature profiles measured at the APPA monitoring point (see Fig. $1 \mathrm{~b}$ and $\mathrm{c}$ and Fig. 1d for typical profiles in winter and in summer, respectively) were applied uniformly over the whole lake. Since temperature profiles, which are measured monthly,

Tab.1. Simulations characteristics for each scenario.

\begin{tabular}{lccc} 
ID & Wind & Temperature & Mean wind speed \\
F1 & 17 January 2013 & 22 January 2013 & $14.3 \mathrm{~m} \mathrm{~s}^{-1}$ \\
\hline F2 & 12 March 2013 & 13 March 2013 & $15.8 \mathrm{~m} \mathrm{~s}^{-1}$ \\
\hline F3 & 5 March 2015 & 18 February 2015 & $15.3 \mathrm{~m} \mathrm{~s}^{-1}$ \\
\hline W1 & 7 February 2011 & 14 March 2011 & $1.8 \mathrm{~m} \mathrm{~s}^{-1}$ \\
\hline W2 & 2 March 2012 & 13 February 2012 & $1.7 \mathrm{~m} \mathrm{~s}^{-1}$ \\
\hline W3 & 27 January 2016 & 19 January 2016 & $1.7 \mathrm{~m} \mathrm{~s}^{-1}$ \\
\hline S1 & 16 June 2012 & 5 June 2012 & $2.8 \mathrm{~m} \mathrm{~s}^{-1}$ \\
\hline S2 & 29 July 2012 & 16 July 2012 & $3.9 \mathrm{~m} \mathrm{~s}^{-1}$ \\
\hline S3 & 19 August 2012 & 21 August 2012 & $2.6 \mathrm{~m} \mathrm{~s}^{-1}$
\end{tabular}


were not available on the exact day chosen as reference for generating the wind field, data from the closest days were adopted. The discrepancy between the dates of the wind and temperature scenarios (Tab. 1) is not critical here, since simulations are meant to associate typical wind pattern to corresponding plausible stratification conditions in different seasons.

A spin-up of 2 days resulted enough to remove the influence of initial conditions in the surface layer, while not significantly modifying the imposed thermal stratification. Accordingly, as a compromise between the reduced influence of the initial conditions and the deterioration of the thermal stratification due to vertical diffusion under adiabatic hypothesis, the third simulation day was used as representative of fully developed flow conditions. Considering adiabatic conditions allowed us to make the analysis of the results more straightforward, focusing on the direct effects of wind pattern, seasonal stratification,
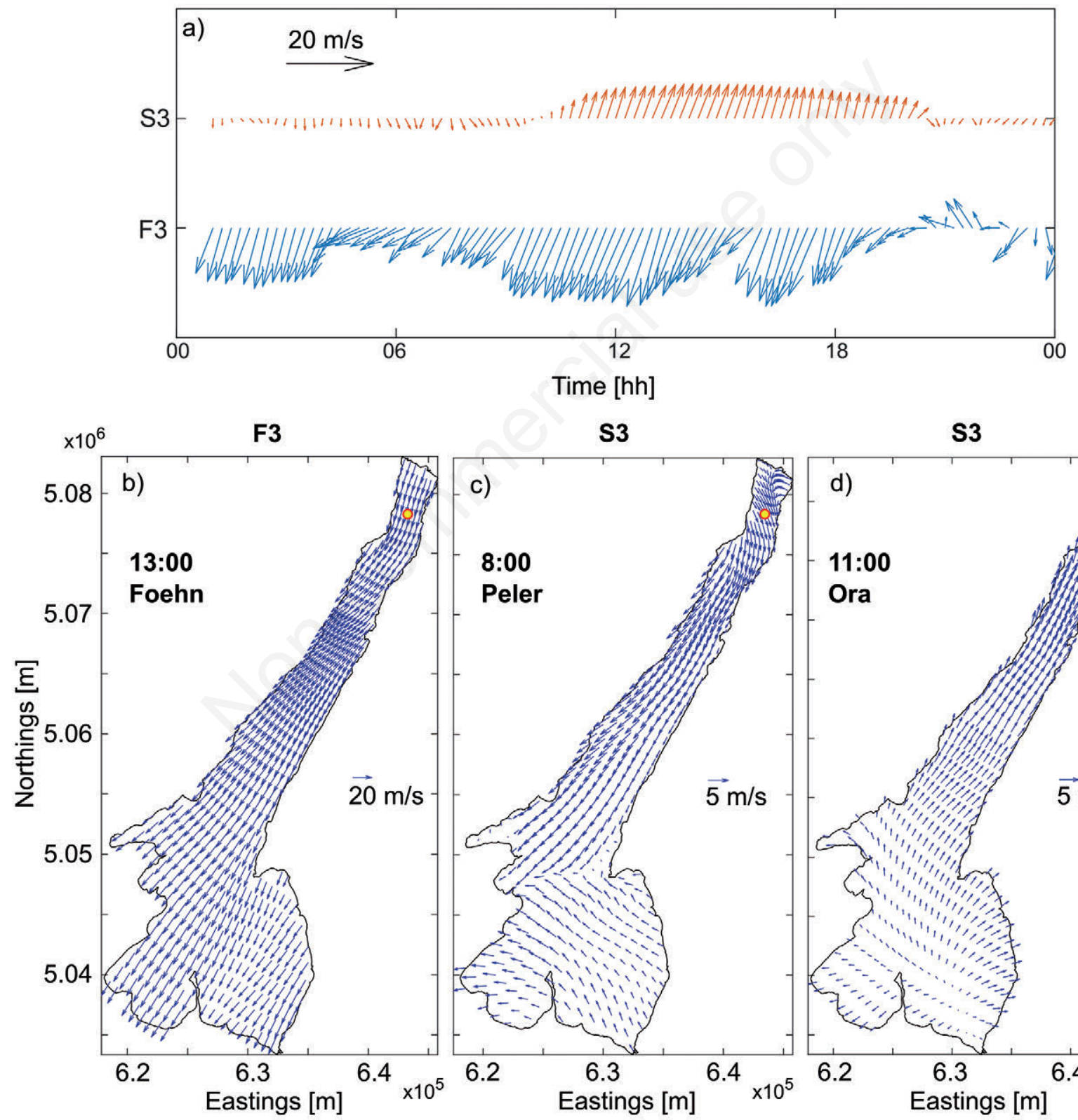

S3

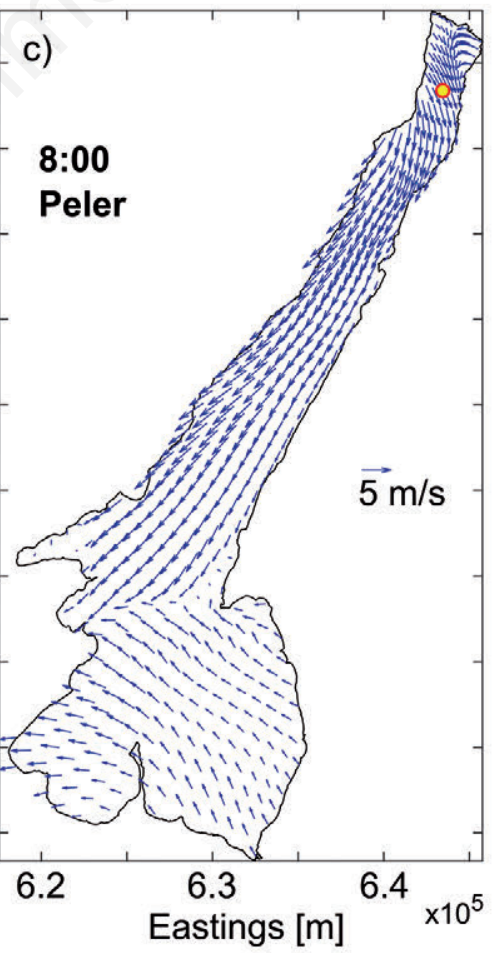

S3

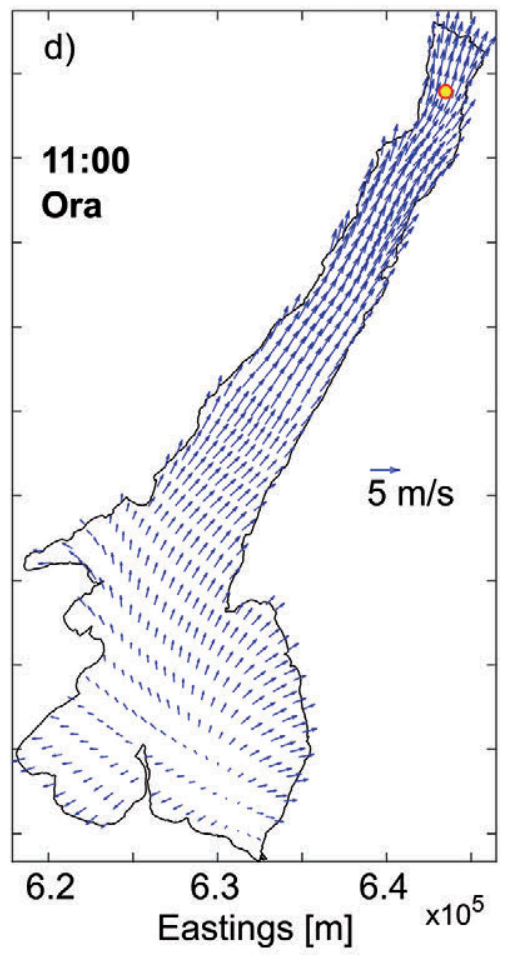

Fig. 2. a) Simulated diurnal wind cycles at $10 \mathrm{~m}$ above ground level for the F3 and S3 scenarios at the APPA point (Fig. 1). Simulated wind field for (b) Föhn wind in F3 winter scenario, (c) 'Peler' and (d) 'Ora del Garda' breezes in S3 summer scenario. Time is given in $\mathrm{UTC}+1$ (local time zone). 
and Earth's rotation, while filtering out the additional complexity of surface heat fluxes parametrization.

\section{Particle tracking model}

Trajectories of individual particles released in the computational domain were traced through the particletracking module available within the Delft3D suite (Delft3D-Part). The model processes flow data from the hydrodynamic model to compute transport and mixing in the mid-field. The effects of dispersion were neglected, so that advection is the only driver of Lagrangian particles. Non-buoyant particles (i.e., having the same density as the ambient water) were released at 318 locations uniformly distributed in the surface layer of the computational domain. In each location 100 particles were instantaneously released within a radius of $10 \mathrm{~m}$.

Five additional release points were placed in geographically significant positions: Torbole (T), Malcesine (M), Limone (L), San Felice del Benaco (SFB), and Sirmione (S) (Fig. 1e). Particles were instantaneously released at the beginning of the third simulation day (00:00) of the hydrodynamic model (i.e., at the end of the 2-day spin-up period). In Lagrangian simulations the time step was 15 minutes (i.e., the time interval of flow data storage) and the total simulation time was two days (i.e., the third and the fourth days of the simulations). Additional simulations were performed with different release times $(06: 00,12: 00,18: 00$, and 24:00 of the third day of the hydrodynamic simulation) to test the sensitivity of the Lagrangian patterns to the instantaneous flow field. As shown in the Supplementary Material, the qualitative characterization of the trajectories walked after two days of simulation was substantially insensitive from the release time.

\section{Residual transport}

The analysis of simulation results is carried out referring to both the Eulerian flow field and the Lagrangian trajectories, with a specific focus on the residual circulation, defined here as the time-averaged velocity field resulting from the third day of each hydrodynamic simulation. We analyzed the factors affecting the outcoming circulation and transport patterns and mostly investigated the effects of bathymetry, wind intensity and direction and Earth's rotation.

The most important transport mechanisms in lakes are produced by wind drag and by momentum transfer from the surface water to the underlying water mass, mostly by means of turbulent vertical exchanges described through the concept of eddy viscosity. In the simplest ideally-shaped lakes, this direct action simply moves water downwind, possibly with a return flow at the bottom (Heaps, 1984), whereas more complex dynamics arise for real lakes especially when stratification is present. Nevertheless, in large and deep water bodies, water circulation can be significantly affected by the Coriolis force. The transport is associated with a spiral flow for which the standard theory (Hutter et al., 2011) provides an estimate of the reference depth (thickness of the Ekman layer),

$D_{E}=\sqrt{\frac{2 v_{z 0}}{f}}$

where $v_{z}$ is the vertical eddy viscosity $f=2 \Omega \sin \varphi$ is the Coriolis frequency, with $\Omega=7.2921 \times 10^{-5} \mathrm{rad} \mathrm{s}^{-1}$ the angular speed of Earth's rotation, and the subscript 0 refers to the constant values used to derive the analytical solution. In an infinitely deep water body, the vertically integrated transport $q_{\mathrm{E}}$ (per unit length, hence in $\mathrm{m}^{3} \mathrm{~s}^{-1} \mathrm{~m}^{-1}$ ) occurs in the lateral (i.e., cross-wind) direction, and can be estimated as

$q_{E}=\frac{\tau_{w}}{\rho_{0} f}$

where $\tau_{\mathrm{w}}$ is the wind stress and $\rho_{0}$ the water density. Corrections to $q_{\mathrm{E}}$ over finite depths can also be obtained analytically (Hutter et al., 2011).

It is often claimed that the effect of Coriolis force can be neglected in lakes narrower than the Rossby radius $L_{\mathrm{R}}=U_{\mathrm{s}} / f$, where $U_{\mathrm{s}}$ is a reference value of water velocity at the surface. Indeed, $L_{\mathrm{R}}$ is the radius of theoretically circular trajectories associated with inertial currents, whose period is $T_{\mathrm{i}}=2 \pi / f$. However, Earth's rotation can also significantly modify the large-scale circulation in narrow lakes where inertial currents cannot develop.

In an elongated narrow lake where the wind field is forced by the adjacent topography to blow along the lake's main axis, the Coriolis force may induce a secondary lake circulation orthogonal to the wind direction, generating onshore downwelling and upwelling. Toffolon (2013) derived an analytical relationship to estimate the secondary circulation in lakes shallower than $D_{\mathrm{E}}$ under simplified conditions (rectangular domain, steady state, constant viscosity). In this case, the lateral transport per unit length can be quantified as:

$q_{T}=\alpha \frac{\tau_{w} D_{r}^{4}}{\rho_{0} v_{z 0}^{2}} f$

where $D_{\mathrm{r}}$ is the depth of the equivalent rectangular domain, and the dimensionless coefficient $\alpha$ depends on turbulence anisotropy and bottom friction. 
Although in principle none of the above analytical expressions for the lateral transport is strictly valid for the general case of enclosed basins, both Equations (2) and (3) are linearly dependent on the wind shear stress, which can be empirically related to wind speed as $\tau_{\mathrm{w}}=\rho_{\mathrm{a}} C_{\mathrm{d}} W^{2}$, where $W$ is the wind speed, $\rho_{\mathrm{a}}$ the air density, and $C_{\mathrm{d}}$ the drag coefficient. Hence, as a first approximation, we can reasonably assume that the theoretical lateral transport per unit length can be expressed as

$q_{t h} \alpha W^{2}$

while further attempts towards the definition of an improved relation for the lateral transport are beyond the scope of the present analysis. An analogous scaling with the square of the wind speed was also successfully used to quantify coastal downwelling due to inshore Ekman transport in the larger and deeper Lake Baikal (Piccolroaz and Toffolon, 2013, 2018).

The analytical dependence suggested by Equation (4) is here tested with the numerically evaluated, mean lateral transport per unit length $q_{\text {lat }} Q_{\text {lat }} / L_{\text {long }}$, where $L_{\text {long }}$ is the length of the examined longitudinal cross-section $C L$, and

$Q_{\text {lat }}=\int_{0}^{\text {Llong }} \int_{0}^{D_{c}} \bar{u}_{\text {lat }} d z d x_{\text {long }}$

is the total transport flowing through it (expressed as $\mathrm{m}^{3}$ $\mathrm{s}^{-1}$ ). In Equation (5), $\bar{u}_{\text {lat }}$ is the lateral velocity (orthogonal to the main axis of the lake) varying with depth $z$. The vertical integral (5) is calculated from the surface to the inversion depth $D_{\mathrm{c}}$, which represents the center of the secondary circulation, i.e., the depth where $\bar{u}_{\text {lat }}$ changes sign.

\section{RESULTS}

\section{Winter cases}

In this section, results from selected simulations are presented for Föhn wind (F3) and ordinary breezes (W2 and W3) scenarios. Similar patterns from F1, F2 and W1 can be found in the Supplementary Material.

\section{Föhn wind scenarios}

Simulations were run for three periods in winter when stratification was weak (Fig. 1c) and the Föhn wind blew from the north-east (Fig. 2 a,b). Residual surface currents (Fig. 3a) are directed from north-east to south-west along the lake longitudinal axis, as surface water is driven downwind by the wind shear stress. The flow field is almost uniform in the northern, elongated, narrow part of the basin, where water is channeled between the steep shores towards the southern, wider part. Flow deviates to the right relative to the wind direction due to the effect of Earth's rotation, and no gyre circulation develops in the surface layer. Particle tracks (Fig. 3d) confirm the flow field described by the residual circulation. During the twoday Lagrangian simulation, particles released in the northern part of the basin travel a 5-20 km distance range, with a clear deviation to the right relative to the wind direction.

The strong wind speed $\left(W \sim 15 \mathrm{~m} \mathrm{~s}^{-1}\right)$ persistently blowing over the lake induces velocities sometimes larger than $\sim 30 \mathrm{~cm} \mathrm{~s}^{-1}$ at the lake surface. This is a rather large value in lakes, but it is consistent with typical observations of the wind factor $U_{\mathrm{s}} / W$ of $1.5-3 \%$ (Henderson-Sellers, 1988; Monismith and Macintyre, 2010). A large-scale vertical circulation is induced in the longitudinal cross section CL (Fig. 4a), with water moving towards the south at the surface, and towards the north in the deeper layers, in accordance with the classical description (Lemmin and D'Adamo, 1996; Wang et al., 2000). An almost closed secondary circulation moves the surface water westward, producing downwelling close to the western shore, a return bottom water flow eastward, and upwelling rising on the eastern shore. An example of this secondary circulation is provided in Fig. $4 \mathrm{~b}$ for the northern transverse cross section CT1, located in the central part of the narrow and elongated sub-basin.

The behavior in the southern sub-basin is more complex because of strong inhomogeneities both in the shape and in the bathymetry of the lake. Two secondary circulations develop in CT2 (Fig. 4c), in which two distinct sub-sections are separated by the submerged ridge from the peninsula of Sirmione to Punta San Vigilio. A return flow occurs only in the deeper regions, whereas over the ridge the whole water column is set in motion with a uniform velocity profile.

\section{Local breezes scenarios}

The effect of winter breezes on lake's circulation was investigated under weak thermal stratification (Fig. 1b). In this case, winds are more gentle and characterized by high variability, space and time, in both intensity and direction, with cold and dense air descending towards the lake during night and in the morning, and warmer lake breezes blowing from the lake to the northern shores in the afternoon. Surface water velocities are one order of magnitude smaller $\left(\sim 1 \mathrm{~cm} \mathrm{~s}^{-1}\right)$ than in the previous case due to the lower intensity of breezes $\left(1-5 \mathrm{~m} \mathrm{~s}^{-1}\right)$. Residual circulations (Fig. 3 b,c) appear much more complex than those observed under Föhn wind conditions. A counterclockwise gyre develops close to the northern border of the lake, where the wind regime is dominated by alternating northerly and southerly weak thermally- 


\section{Residual surface velocity fields}
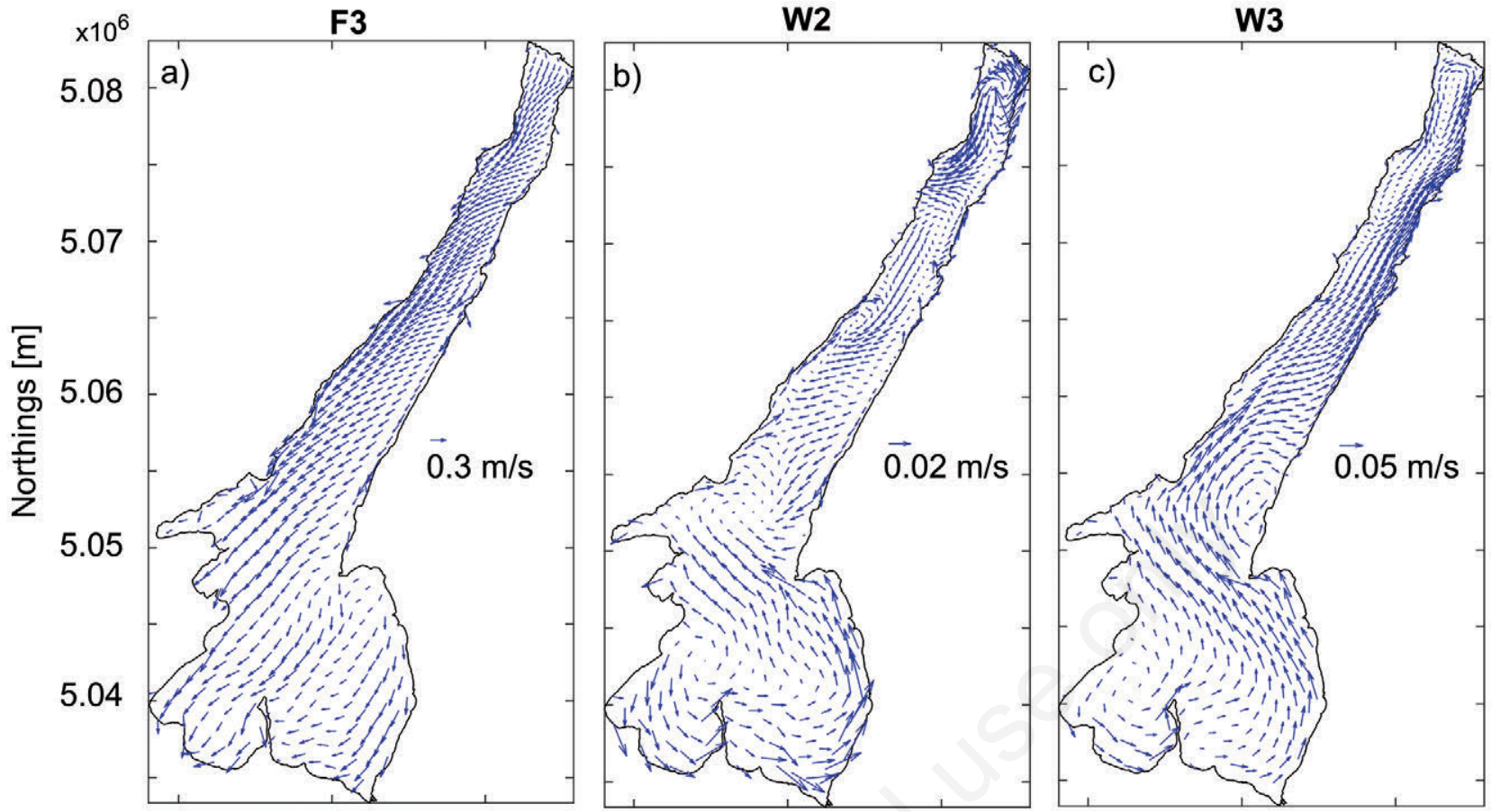

Particle trajectories
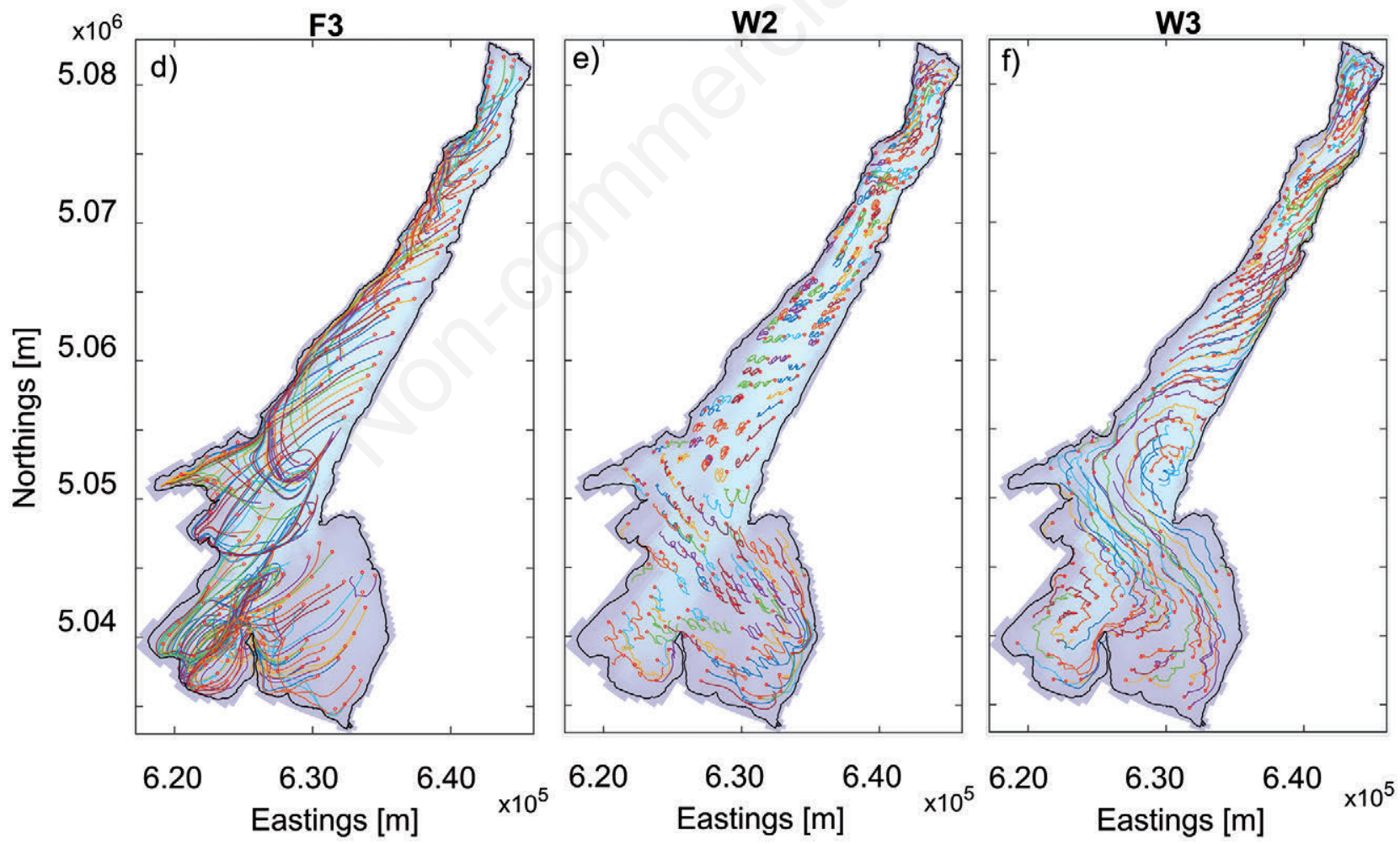

Fig. 3. Horizontal transport in winter simulations. Top plots: residual surface currents from simulations F3 (a), W2 (b), W3 (c), obtained by a time average over day 3. Bottom plots: particle trajectories after two-day Lagrangian tracking in simulations F3 (d), W2 (e), W3 (f). Particle positions are computed through an average over 100 particles in release points and plotted at 15-min intervals from the release time (00:00 of hydrodynamic simulation day 3) to the end of Lagrangian simulation (24:00 of hydrodynamic simulation day 4). Note: $60 \%$ of the total number of trajectories are plotted after a random sampling to ease the comprehension of the figure. 
driven winds. The resulting dynamics are similar to those developing in summer conditions and described in the following section.

More heterogeneous dynamics develop in the central and southern parts of the lake, where breezes are not as regular and uniform as those in the northern part, and topographic effects are more significant due to the complex and shallower bathymetry.

Particle tracks reveal that Lagrangian transport is very small during simulation W2 (Fig. 3e), because the local breezes change direction and intensity during the day, then daily-averaged displacements are shorter. All over the lake, particles drift around the release points during the two-days Lagrangian simulation, along curved trajectories resulting from the combined effect of alternating wind direction and Earth's rotation $\left(L_{R} \sim 100\right.$ $\mathrm{m}$ in this case).

\section{Summer cases}

Residual circulations in summer cases are dominated by the diurnal variability of the wind field, similar to winter breezes, but with more intense winds and clear alternating directions. Additionally, water motion is complicated by the effects of strong thermal stratification. Fig. 5a-c shows the residual circulation for the three simulated summer scenarios. The time and spatial average of wind speed for the three summer simulations is $W \sim 2$ $\mathrm{m} \mathrm{s}^{-1}$ (Tab. 1), although large peaks up to $10 \mathrm{~m} \mathrm{~s}^{-1}$ can be reached during the afternoon development of the 'Ora del Garda' wind. Wind-induced average surface velocities are $\sim 5 \mathrm{~cm} \mathrm{~s}^{-1}$, in agreement with summertime observations in other subalpine lakes (e.g., in Lake Geneva, Lemmin and D'adamo, 1996; Razmi et al., 2013).

In the narrow and elongated part of the lake, counterclockwise gyres develop: a small one close to the northern shore (G1) and a larger one in the central part of the lake (G2), with slightly different characteristics from one simulation to another. The Lagrangian trajectories (Fig. 5 d-f) confirm a general gyre-like transport. A zoom from the S1 simulation (Fig. 6a) shows that particles released close to the shores are dragged by the surface flow and walk long distances $(\sim 10 \mathrm{~km})$ along the shore, whereas off-shore trajectories follow the residual counterclockwise gyre, also oscillating at the inertial period ( $T_{\mathrm{i}}=16 \mathrm{~h} 45 \mathrm{~min}$, with a Rossby radius $L_{\mathrm{R}}$ ranging between $200 \mathrm{~m}$ and $1 \mathrm{~km}$, depending on the local velocity). This is consistent with typical near-/off-shore dynamics observed

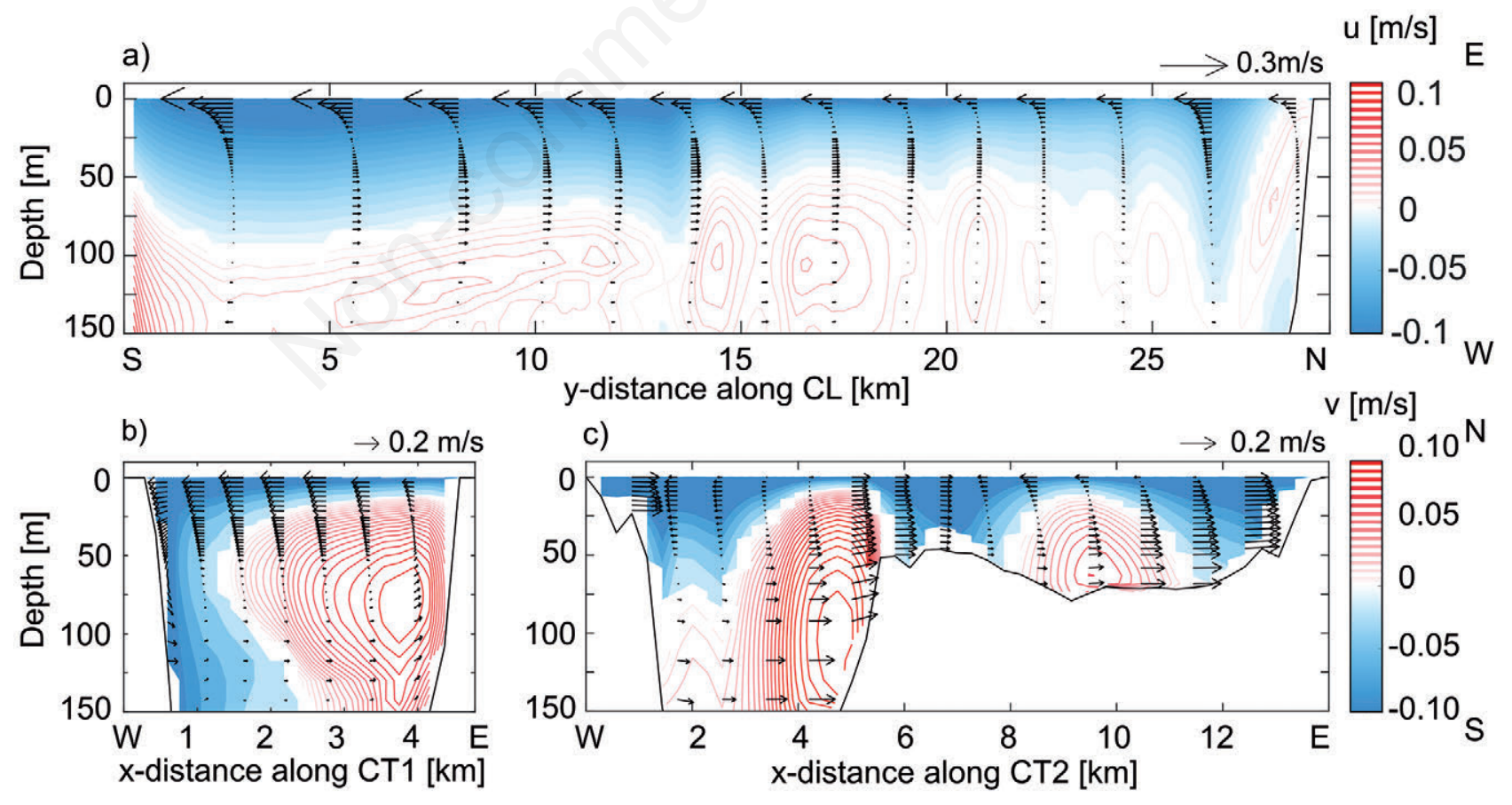

Fig. 4. Residual cross-section circulation from winter simulation F3, obtained by a time average over day 3: (a) longitudinal section CL, (b) northern transverse section CT1 and (c) southern transverse section CT2. The contour plot shows the magnitude of the orthogonal component of the velocity; contour lines are plotted for positive velocities, filled contour plot is for negative velocities. Arrows indicate the circulation in the section. To ease the comprehension of the figure, not all grid cells are drawn in quiver plot. Further plots can be found in the Supplementary Material. 


\section{Residual surface velocity fields}

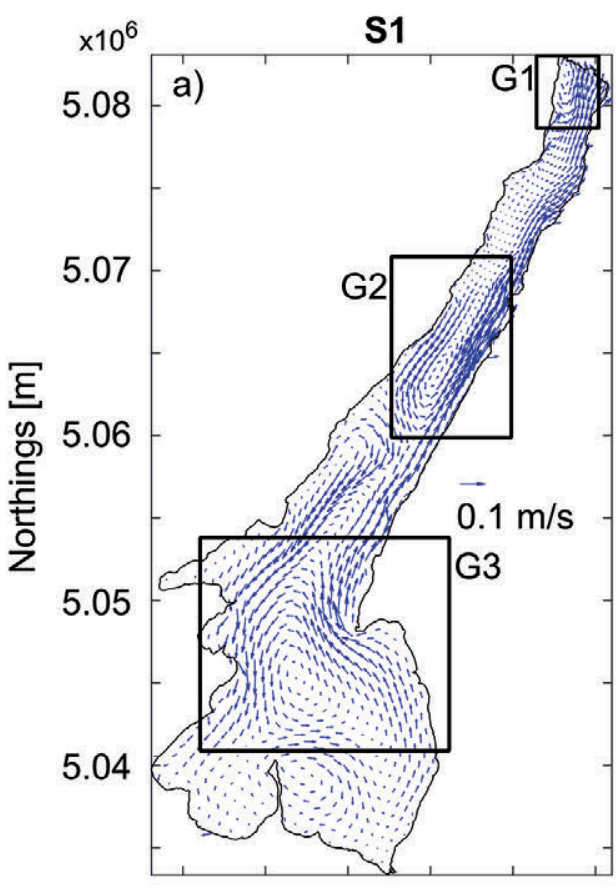

S2

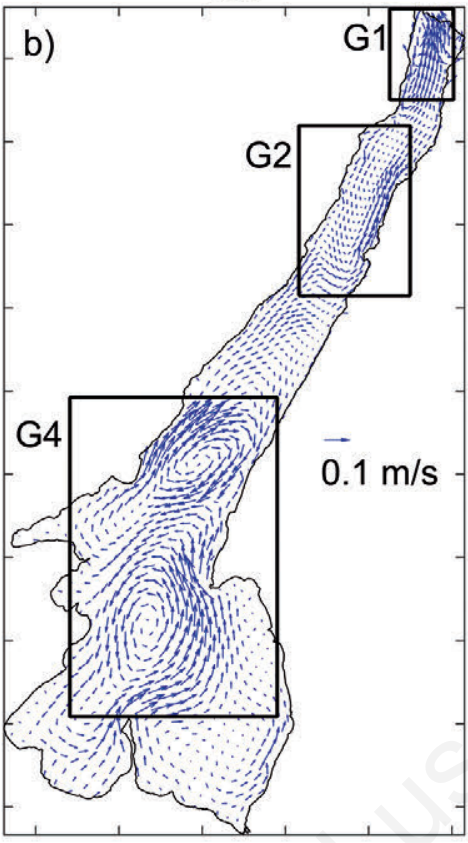

Particle trajectories

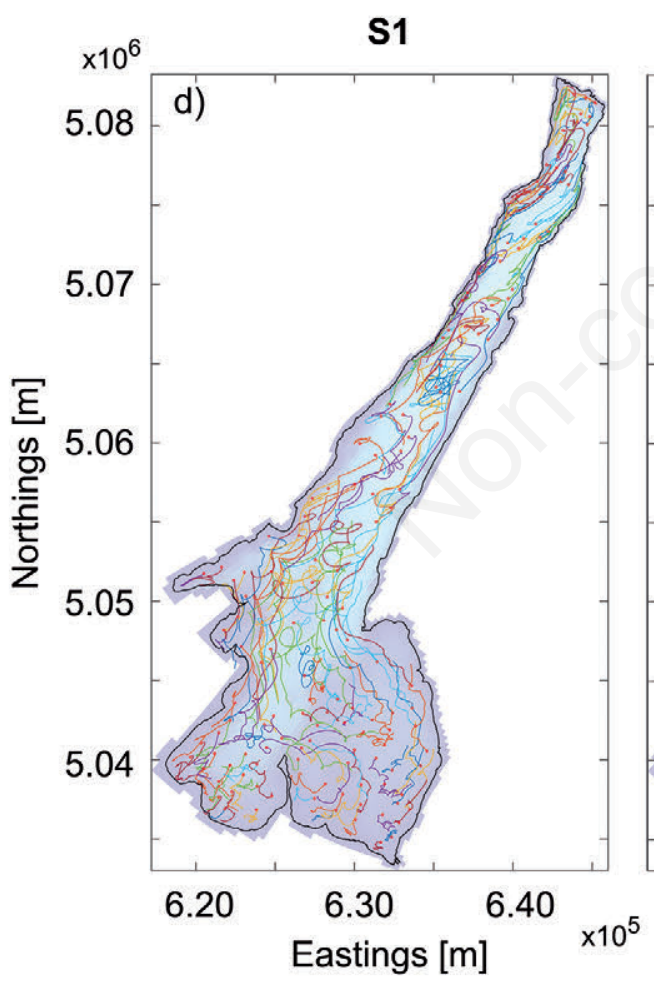

s2

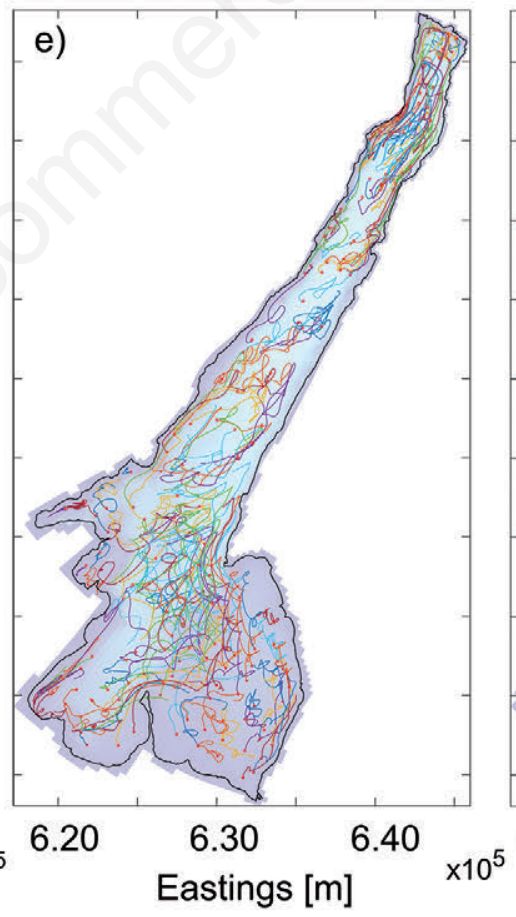

S3

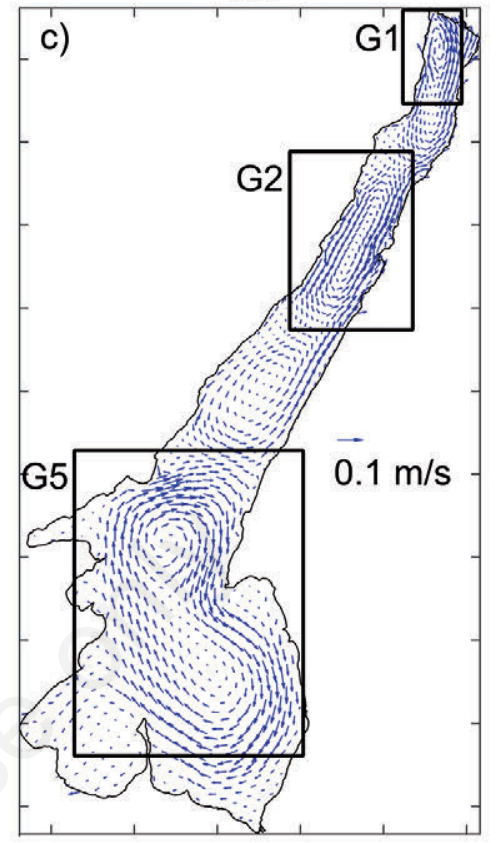

S3

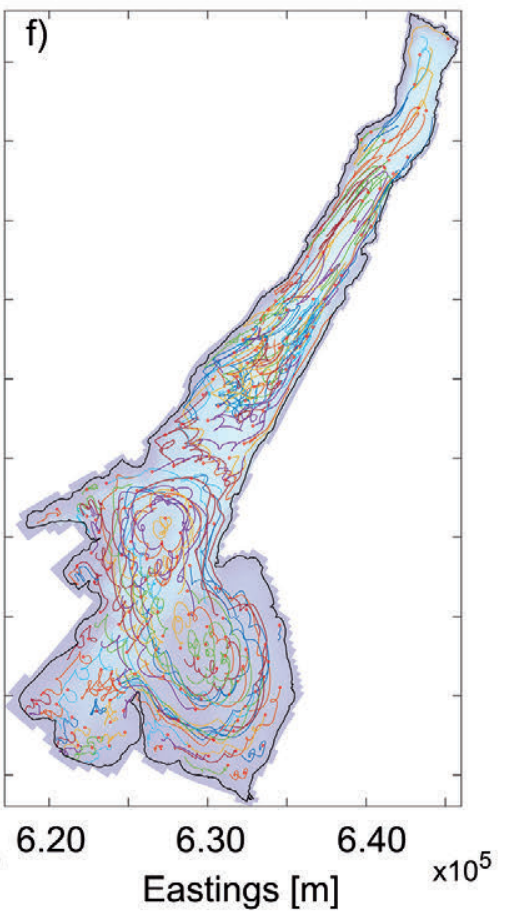

Fig. 5. Horizontal transport in summer simulations. Top plots: residual surface currents from simulations S1 (a), S2 (b), S3 (c), obtained by a time average over day 3. Relevant gyre patterns are framed in boxes G1-G5. Bottom plots: particle trajectories after two-day Lagrangian tracking in simulations S1 (d), S2 (e), S3 (f). Particle positions are computed through an average over 100 particles in release points and plotted at 15-min intervals from the release time (00:00 of hydrodynamic simulation day 3$)$ to the end of Lagrangian simulation (24:00 of hydrodynamic simulation day 4). Note: $40 \%$ of the total number of trajectories are plotted after a random sampling to ease the comprehension of the figure. 
from drifters experiments during summer stratification (Rao and Murthy, 2001).

In the southern wider part of the lake, the residual surface circulation displays a strong variability. A single counterclockwise gyre develops in simulation S1 (Fig. 5 a,c G3). A two-gyre circulation develops in simulation S2 (G4 in Fig. 5 b,e), composed by a clockwise gyre in the central part and by a southern larger counterclockwise gyre, without involving particles released $3 \mathrm{~km}$ east of Sirmione (Fig. 6b). Finally, two clockwise gyres ensue in simulation S3 (G5 in Fig. 5 c,f), connected through an eternal lemniscate-shaped circulation. No exchange occurs with the Desenzano Bay, where an additional small counterclockwise circulation develops. A more detailed analysis on Lagrangian tracks for the $\mathrm{S} 3$ simulation is proposed in Fig. $6 \mathrm{c}$ for a few particles involved in the twogyre circulation. For these particles the alternate pattern of the wind (period of approximately 24 hours) interacts with inertial trajectories, making the interpretation of the whole dynamics more complex.

The greatest differences among summer simulations are detected in the southernmost part of the lake, where bathymetry likely dominates the response of the basin to an extremely variable wind forcing. In addition, inertial currents can develop in this part of the lake where low velocities occur $\left(U_{\mathrm{s}} \sim 5 \mathrm{~cm} \mathrm{~s}^{-1}\right)$ and consequently the Rossby radius is small $\left(L_{\mathrm{R}} \sim 500 \mathrm{~m}\right)$. Particles following inertial trajectories are those that are not involved in strong surface currents and those released where space is enough for such trajectories to develop. Similar patterns are not detected in the northern part of the lake, because of its narrow shape and the higher velocities $\left(L_{\mathrm{R}}\right.$ up to $\sim$ $1 \mathrm{~km}$ with an average surface velocity $U_{\mathrm{s}} \sim 10 \mathrm{~cm} \mathrm{~s}^{-1}$ ). Instead, all summer simulations show a counterclockwise gyre (G2) under similar wind forcing in the northern part of the lake, consistently with its regular shape.

\section{DISCUSSION}

\section{Wind variability}

The results of numerical simulations highlight that circulation patterns in Lake Garda can highly vary according to the spatial distribution and time variation of the wind forcing. It has been shown that the alternating direction of the breezes in summer (Fig. $5 \mathrm{a}-\mathrm{c}$ ) and winter days (Fig. 3 b,c) produces gyre-like structures that cannot be captured using a uniform forcing, which in turn triggers unidirectional currents (Fig. 3a for winter Föhn simulations). An additional proof that the inhomogeneity of the wind field critically influences transport processes in Lake Garda comes from a summer simulation which was performed with the same setting as for scenario S3, but with a spatially uniform wind field (see Supplementary Material for more details). In such a test the gyre structures are completely lost in both residual surface circulations and Lagrangian tracks. Even in the northern region (Fig. 2 c,d) where 'Peler' and 'Ora del Garda' breezes blow almost uniformly for some hours, gyres do not occur under the uniform wind forcing, suggesting that the transition from the northerly to the southerly breezes plays a key role in the development of

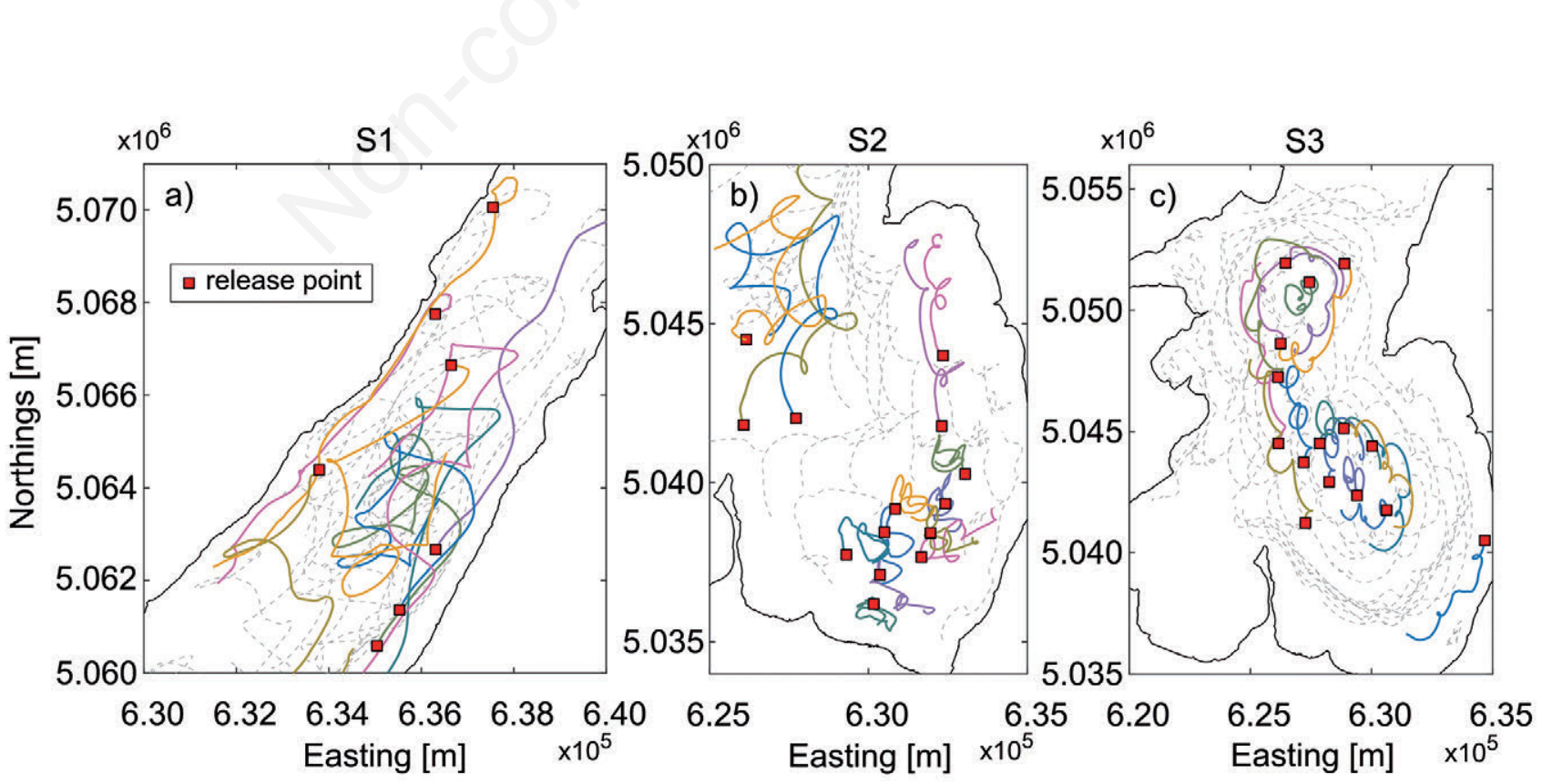

Fig. 6. Details from Fig. 5 of Lagrangian trajectories in simulations S1 (a), S2 (b) and S3 (c). Continuous lines are drawn for the mean paths of selected releases and dotted lines for mean trajectories from neighbor releases. Red squares represent the starting points. 
complex residual patterns. Even though a uniform wind forcing has been widely found to be suitable for predicting some phenomena, internal wave motions amongst all (Laval et al., 2003), the spatial variability of the wind stress turns out to be fundamental in reproducing basinscale cyclonic gyres in Lake Garda, which is consistent with what has been already observed by Strub and Powell (1986); Lemmin and D'adamo (1996); Laval et al. (2005). Such an external forcing was computed through an atmospheric model that was specifically set up for the study region (Giovannini et al., 2014b) in accordance with similar experiences in other lakes (Pan et al., 2002; Leon et al., 2007). This approach is preferable in lakes located in sub-alpine regions where the spatial variability of the wind field is due to terrain complexities (Laiti et al., 2013a; Laiti et al., 2014; Giovannini et al., 2015; Giovannini et al., 2017), as Valerio et al. (2017) observed in Lake Iseo. The results presented here suggest that the interplay between lake and atmosphere dynamics should be taken into account also in the case of Lake Garda. In this regard, the improvement of more sophisticated, fully coupled simulations of lake processes by means of hydrodynamic and atmospheric models is a challenge for future research work (Serafin et al., 2018).

\section{Lagrangian transport}

The particle tracking simulations provide interesting elements to understand the transport processes in the lake, which could not be obtained by the residual circulations alone, especially in the case of alternate wind patterns. In addition, Lagrangian trajectories confirm that the residual gyres shown in Figs. 3 and 5 are not artifacts of the averaging procedure as they are representative of the mean flow field, actually dragging the released particles in a swirling motion. Stocker and Imberger (2003) deployed Lagrangian drifters in Lake Kinneret and detected a similar daily-averaged cyclonic circulation, as previously simulated by Pan et al. (2002).

Fig. 7 shows the statistical distribution (box plots) of horizontal and vertical distances spanned by the Lagrangian particles at the end of the two-day simulations. Horizontal transport (Fig. 7a) is greater in winter Föhn scenarios due to the strength and persistence of the wind, as expected. North-eastern releases (i.e., Torbole and Malcesine) are transported $\sim 10-25 \mathrm{~km}$, so that they can almost reach the lower end of the trunk region in two days. Conversely, a distance of less than 5 $\mathrm{km}$ is covered after two days for summer and winter typical breeze scenarios. As a general trend, the horizontal displacements in the northern trunk, where strong longshore currents develop (under both the Föhn wind and the summer breezes 'Ora del Garda' and 'Peler'), are larger than those in the southern basin (San Felice sul Benaco), where gyres develop. This is consistent with the observations of Razmi et al. (2014) in Lake Geneva, who found that the residence time of simulated Lagrangian tracers are shorter for wind forcing aligned with the shoreline, eventually producing long-shore currents, and longer when wind is diverted from the longitudinal axis of the lake, with consequent gyre formation. Vertical displacements (Fig. 7b) in winter Föhn scenarios are related to downwelling phenomena produced by the Coriolis force along the western shore. In the northern trunk, particles released in Limone (to the right with respect to the wind direction) reach the largest depths, as horizontal movements are constrained within the bay, and downwelling processes are facilitated by the steep shores and by the absence of thermal stratification. This is consistent with what Rao and Schwab (2007) summarized for Great Lakes, where the high wind speeds during winter-spring storms work together with nearly homogeneous temperature profile and topographic variability allowing for a deeper penetration of momentum into the water column and vertical transport, and eventually leading to resuspension events in the nearshore areas. In the southern basin, particles released close to San Felice del Benaco are pulled down by the large-scale circulation moving surface water downwind (southwards), and deep water upwind (northwards).

Under weak winter breezes a lower energy input comes from the wind, which is not unidirectional and does not drive a steady (longitudinal and transversal) circulation like in the previous case. As a result, vertical transport is significantly smaller, even though opposite trends found in eastern (Malcesine) and western (Limone) releases suggest the occurring of downwelling - upwelling processes.

In summer, vertical transport is smaller than that in winter because it is inhibited by the thermal stratification. In the northern part of the lake, where wind blows persistently for some hours, vertical displacements can be related to the combined effect of the coastal upwelling zone balancing along-shore wind stress, Coriolis force, and internal pressure gradients (Rao and Murthy, 2001). In the southern part of the lake, where wind is less intense and with more variable direction, downwelling processes are prevented, and particles tend to stay in the surface layer (final depths less than $10 \mathrm{~m}$ ).

\section{Effects of Earth's rotation}

The effect of Earth's rotation is clearly visible in winter conditions under a synoptic uniform wind, when a closed secondary circulation orthogonal to the wind direction develops in the northern trunk region of the lake. There, the response is as expected in an elongated, laterally confined lake: the strong wind blows southwards and produces downwelling along the western shore and upwelling along the eastern shore.

The effect of Coriolis force can also explain the 
development of the counterclockwise circulation pattern observed in the summer simulations. In fact, instantaneous surface currents follow the alternating direction induced by the 'Peler' and 'Ora del Garda' winds, but the Coriolis force tends to accelerate the right (with respect to the wind direction) part of the flow field. This phenomenon is due to a rightward transfer of high momentum surface water produced by the secondary Ekman-type circulation, while the upwelling of lowmomentum water from deeper regions tends to decelerate the leftward part (Toffolon, 2013). Hence, the counterclockwise gyre turns out as a residual outcome of the higher velocities close to the western shore during the northerly 'Peler' wind and the higher velocities at the eastern shore during the southerly 'Ora del Garda' wind. A similar phenomenon can be observed also in the winter breeze cases.

In order to verify that the two mentioned processes can be ascribed to the rotation of the Earth, additional tests have been performed running the simulations with opposite latitude (i.e. placing Lake Garda in the southern hemisphere). In winter Föhn test simulations the secondary circulation in the transversal cross section CT1 (Fig. 8a) moves water in the opposite direction, with downwelling occurring along the eastern shore and upwelling along the western one, since Coriolis force deviates the flow to the left in the southern hemisphere. In summer test simulations the surface gyres developing in the central part of the northern trunk are clockwise (Fig. 8b), as the Earth's rotation now accelerates the left part of the flow field. Interestingly, both secondary circulations and surface gyre in the southern part of the lake seem not to be affected by a)

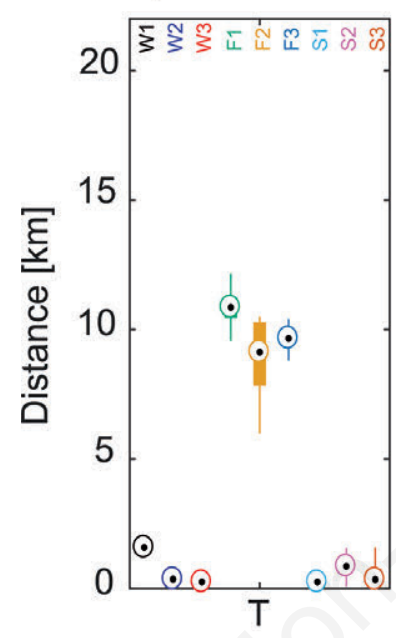

b)

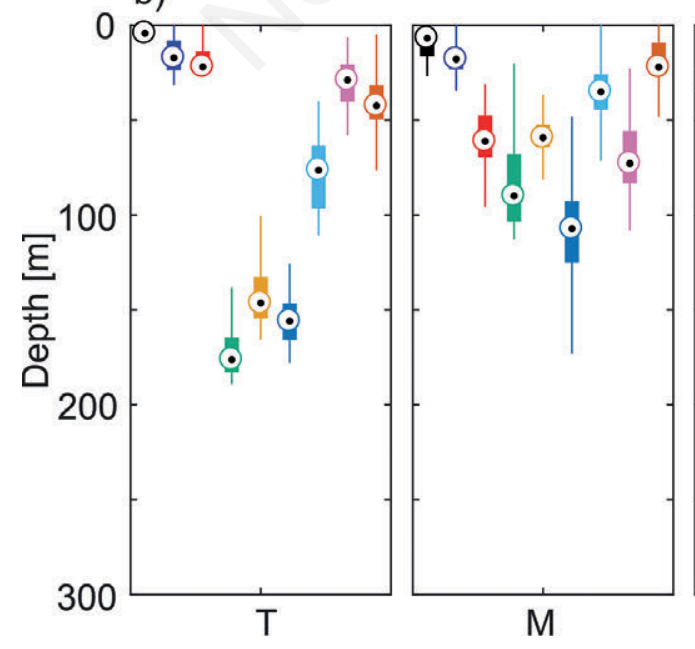

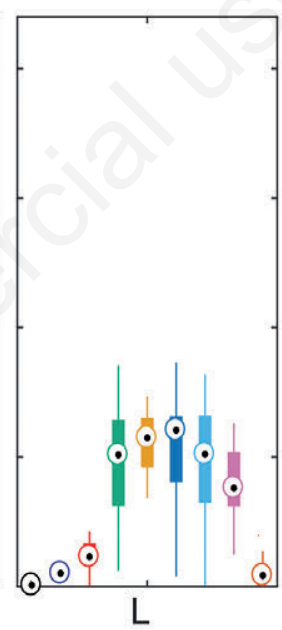
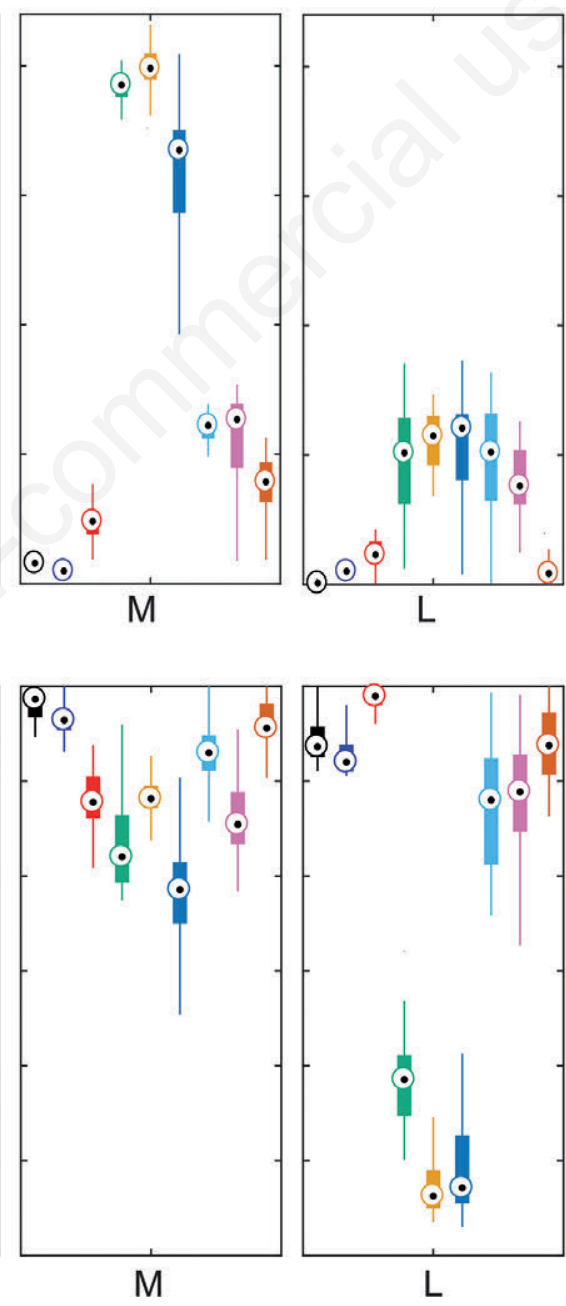

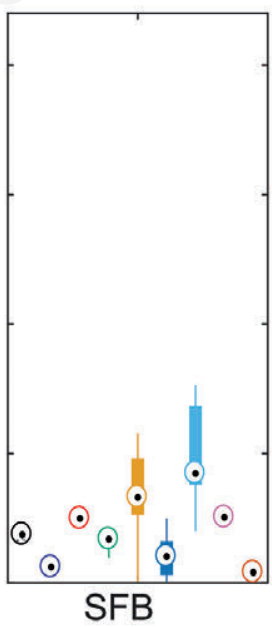

$5^{\text {th }}$ perc

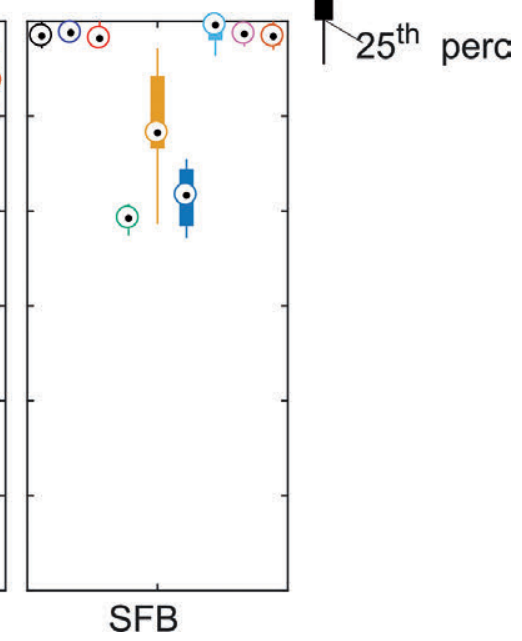

Fig. 7. Statistics of (a) distances traveled after two days and (b) of time-averaged depths reached by particles in Lagrangian winter and summer simulations. Northern releases: Torbole (T), Malcesine (M), Limone (L); southern release: San Felice del Benaco (SFB). 
the change in latitude, suggesting that the complex topography and the shallower bathymetry have much more effect than Earth's rotation on the flow field.

\section{Ekman transport}

The amount of water transported in the northern part of the lake by the Ekman transport can be quantified both in winter and summer. For winter Föhn simulations, the volume of water pulled down close to the shore (i.e., the downwelling) is reasonably the same as the volume moved westward on the surface (i.e., the Ekman-type transport, here computed according to Equation 5), because the secondary circulation is approximately closed in a transverse cross-section of the trunk region. In this case the lateral transport $Q_{\text {lat }}$ (assumed positive in the westward direction) is computed from the surface to a depth of $70 \mathrm{~m}$, where the sign of the transversal velocity changes, identifying the center of the secondary circulation.
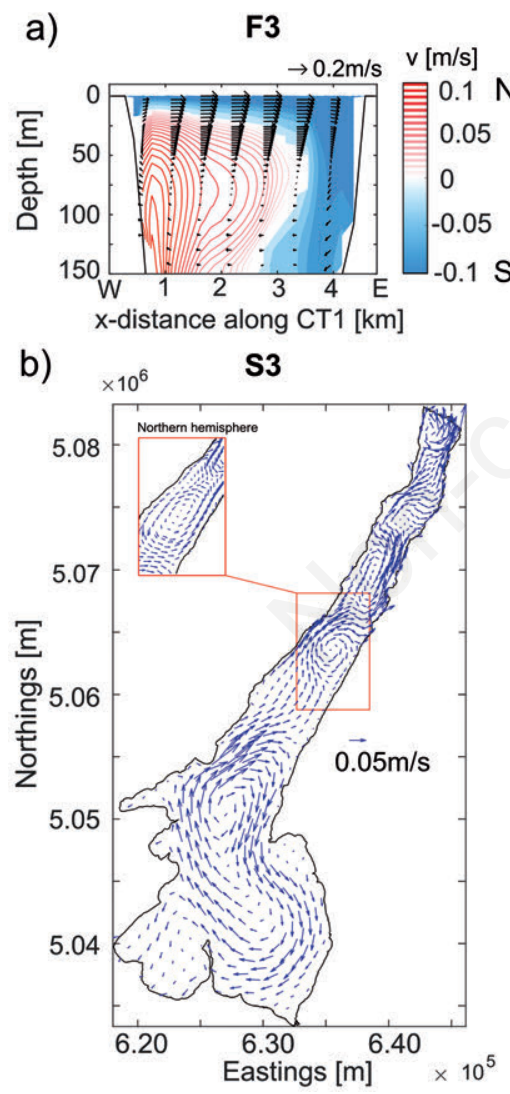

Fig. 8. Residual circulations from simulations performed inverting the latitude sign (Southern hemisphere): (a) northern transverse cross section CT1 from F3 scenario; (b) surface circulation from S3 scenario. The inset in panel (b) shows the circulation pattern at the real latitude (Northern hemisphere), as seen in Fig. 5c.
On the other hand, when the wind forcing is spatially and temporally varying (breeze scenarios in winter and summer conditions), the computation of the Ekman transport is more challenging because the secondary circulation is not uniformly developed along the northern part of the lake. Based on the results of the hydrodynamic simulations, the lateral transport $Q_{\text {lat }}$ is computed numerically according to Equation (5) across the longitudinal section CL over the first 20-30 m (corresponding to the thickness of the surface layer where velocities are significant).

In Fig. 9, the temporal variability of $Q_{\text {lat }}$ is compared with the wind velocity $W$ for the third and the fourth day of simulations F3 (a), and S3(b). The wind velocity $W$ is computed as an average of the along-axis component of the wind blowing above the CL section. The longitudinal component of the wind is well correlated with the lateral transport across the cross-section CL, which is orthogonal to the wind forcing and assumed to be produced by the Coriolis force. The positive sign stands for southward direction of wind speed and for westward transport of water mass. In the case of strong Föhn wind (Fig. 9a), $W$ and $Q_{\text {lat }}$ keep the same direction, with a temporal shift due to the delay in the response of the lake to a sudden change of the forcing (dotted blue line). By maximizing the cross-correlation, a delay of $\sim 3$ hours has been quantified in simulation F3 (continuous blue
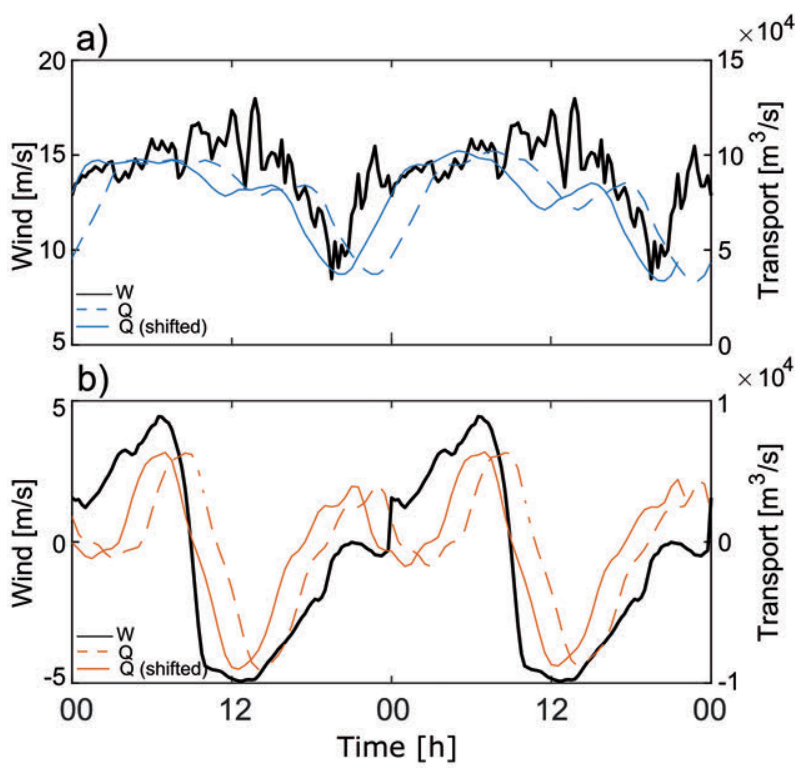

Fig. 9. Time series of longitudinal wind component $W$ (black line), averaged along CL, and total lateral transport $Q_{\text {lat }}$ (colored lines: dotted for the actual transport, continuous for delayed) for simulation F3 (a, $D_{\mathrm{c}}=70 \mathrm{~m}$, delay=3 hours) and S3 (b, $D_{\mathrm{c}}=20 \mathrm{~m}$, delay $=1.5$ hours). Positive sign stands for southward wind intensity and westward transport. 
line). In the summer case (Fig. 9b), the changes in wind direction (southward in the morning, northward in the afternoon, i.e. positive and negative respectively) are reflected in the sign variation of lateral transport (westward in the morning and eastward in the afternoon). Maximum cross-correlation between the two trends suggests a delay $\sim 1.5$ hour in simulation S3 (continuous and dotted orange lines).

The lateral transport is plotted as a function of wind speed (accounting for the estimated time lag) in Fig. 10. Despite some scatter, the quadratic dependence suggested by Equation (4) is approximately found both in winter (Fig. 10a) and in summer simulations (Fig. 10b). The proportionality coefficient is different in the two cases, as it is reasonable because of the different conditions (stratification, vertical eddy viscosity, etc.). Numerical results show that the amount of water transported in the direction orthogonal to the wind is huge in winter Föhn days $\left(Q_{\text {lat }} \sim 8 \times 10^{4} \mathrm{~m}^{3} \mathrm{~s}^{-1}\right.$, eventually producing a significant downwelling along the western shore), and smaller in winter and summer typical breeze days $\left(Q_{\mathrm{lat}} \sim\right.$ $\left.1 \times 10^{4} \mathrm{~m}^{3} \mathrm{~s}^{-1}\right)$.

\section{CONCLUSIONS}

Lake Garda is one of the largest and deepest subalpine lakes, but its hydrodynamic behavior is largely unexplored, and the complexity of its morphology makes it a significant case study to be investigated. To this end, a three-dimensional hydrodynamic model (Delft3D) was used to simulate the typical seasonal circulation associated with realistic wind fields provided by an atmospheric model (WRF), through an off-line coupling from the atmosphere to the lake. To characterize the lake's response to the external forcing, different thermal stratification conditions (from in-situ measurements) and typical space- and time-varying wind patterns (from WRF simulations) were considered to obtain the Eulerian residual (i.e., time-averaged) circulations and the Lagrangian tracks. The analysis highlighted novel aspects of lake's hydrodynamics that can likely be generalized also to other similar contexts. In particular, two main aspects were highlighted.

First, under almost uniform and long-lasting synoptic Föhn winds, winter thermal conditions appear to ease

a)

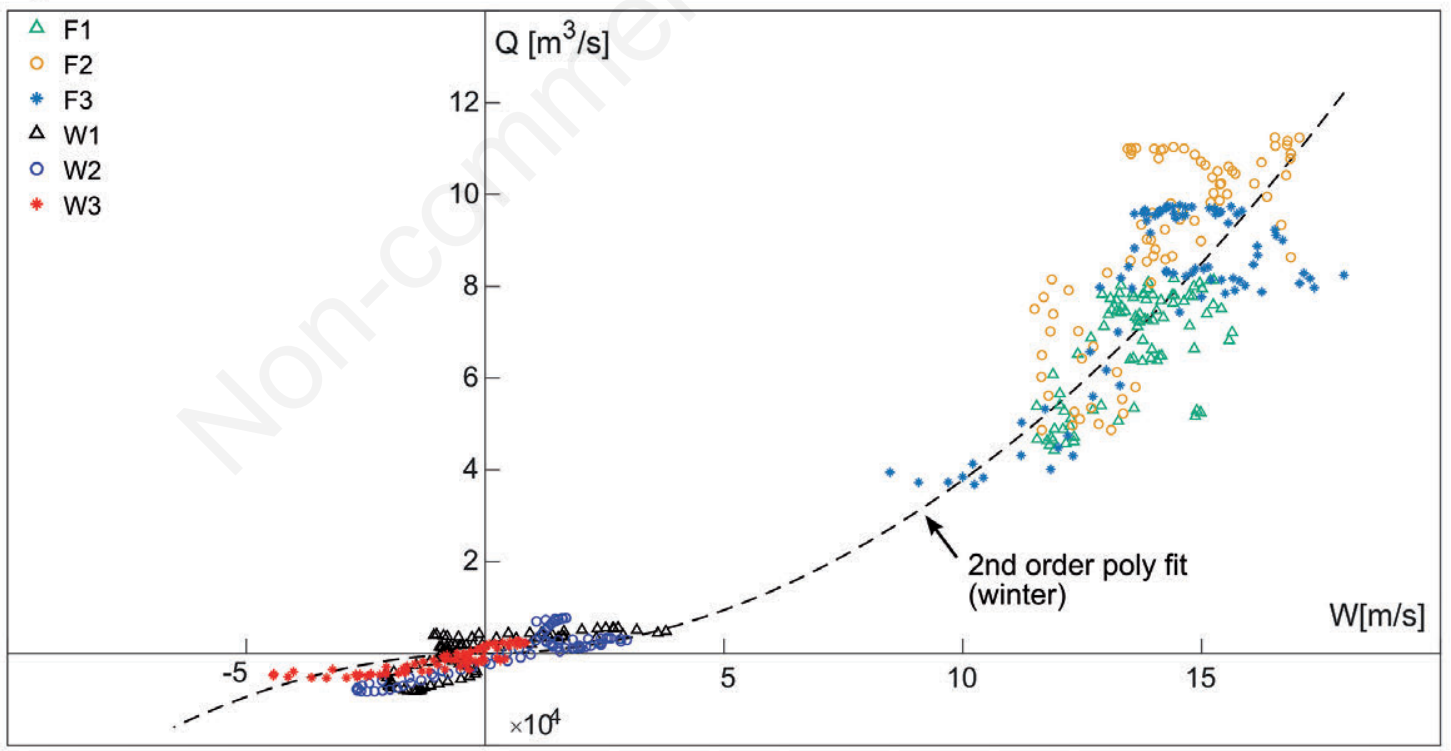

b)

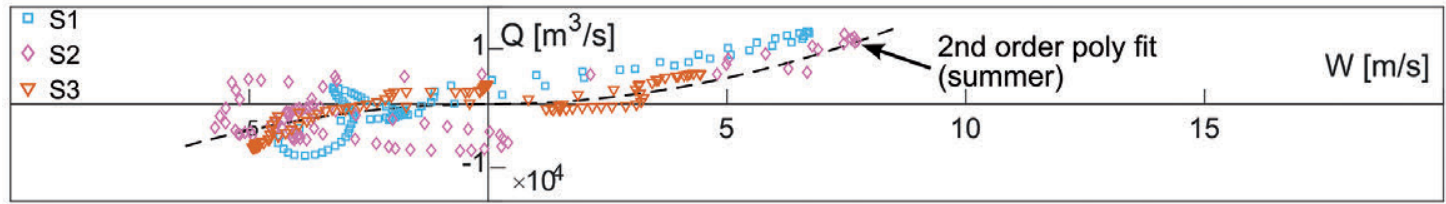

Fig. 10. Lateral transport versus wind speed in all simulations: a) winter Föhn (F1, F2, F3; $\left.D_{\mathrm{c}}=70 \mathrm{~m}\right)$ and typical breezes (W1, W2, W3; $D_{\mathrm{c}}=20 \mathrm{~m}$, delay=3 hours); b) summer breezes $\left(\mathrm{S} 1, \mathrm{~S} 2, \mathrm{~S} 3 ; D_{\mathrm{c}}=20 \mathrm{~m}\right.$, delay $=1.5$ hours $)$. Dotted lines represent quadratic fitting between wind and transport. Positive sign stands for southward wind intensity and westward transport. 
upwelling and downwelling phenomena along the lateral shores of the deep and elongated northern region. The phenomenon can be interpreted as an Ekman-type transport controlled by the effect of Earth's rotation, and the lateral transport can be correlated to the square of the wind speed after accounting for a delay due to the water mass inertia. Similar relationships are expected to be found also in other elongated Alpine and fjord-like lakes, although further analyses are required to get evidence for generally valid conclusions.

Second, the alternating direction of the typical diurnal summer breezes, interacting with the Coriolis force, drives the development of more complex circulation throughout the lake. In particular, the observed counterclockwise gyre in the northern trunk region can be explained as an effect of the Coriolis force tending to accelerate the right part of the flow field. In terms of the residual circulation, this mechanism produces a northward prevalence along the eastern shore, and a southward prevalence along the western shore. Analogous counterclockwise patterns are found also in the winter breeze scenarios, suggesting that the mountain-valley dynamics, dominating the wind diurnal cycle, might be responsible of persistent residual surface currents.

We stress that the present study is intended to be a first step towards the understanding of the hydrodynamics of Lake Garda. While the unavailability of hydrodynamic measurements in the case study did not allow for designing a sophisticated predictive modeling tool, here we provide a first-order characterization of the physical processes occurring in the lake. In this respect, field measurements (Toffolon et al., 2017) have been planned with the support of the present modeling results, and further advances in the understanding of lake dynamics are expected from the synergies between observational evidences and more extensive analyses of model results. We suggest that this kind of modeling exercise could be performed also in other lakes where nothing is known about hydrodynamics, as it can provide useful background information for the optimal planning of field campaigns and insights for local agencies in charge of lake monitoring, triggering a virtuous cycle between modeling, experimental work and management of the lake.

\section{ACKNOWLEDGMENTS}

For hydrodynamic simulations, Lake Garda thermal profiles and the original IGM bathymetry used in this study were provided by the Environmental Protection Agency of the Province of Trento APPA (available upon formal request to acqua.appa@provincia.tn.it). For atmospheric simulations, the initial and boundary conditions were supplied by the 6-hourly National Centers for Environmental Prediction (NCEP) Final Operational
Global Analysis data on 1-degree grids (available for download at: https://rda.ucar.edu/datasets/ds083.3/). For the land use the Corine Land Cover dataset, with a spatial resolution of $100 \mathrm{~m}$, was used, provided by the European Environment Agency (http://www.eea.europa.eu). We thank Menno Genseberger (Deltares) for sharing an initial setup of Lake Garda model. We are also grateful to Henk Dijkstra for many helpful discussions and valuable comments that improved the manuscript.

\section{REFERENCES}

Crosman ET, Horel JD, 2010. Sea and Lake breezes: a review of numerical studies. Boundary-layer Meteorol. 137:1-29.

Defant A, 1909. Berg- und Talwinde in Südtirol [Mountain and valley winds in southern Tyrol]. S. B. Akad. Wiss. Wien, Abt. IIa. 118:553-604.

Giovannini L, Antonacci G, Zardi D, Laiti L, Panziera L, 2014a. Sensitivity of simulated wind speed to spatial resolution over complex terrain. Energy Procedia 59:323-329.

Giovannini L, Laiti L, Serafin S, Zardi D, 2017. The thermally driven diurnal wind system of the Adige Valley in the Italian Alps. Quart. J. Roy. Meteorol. Soc. 143:2389-2402.

Giovannini L, Laiti L, Zardi D, De Franceschi M, 2015. Climatological characteristics of the Ora del Garda wind in the Alps. Int. J. Climatol. 35:4103-4115.

Giovannini L, Zardi D, De Franceschi M, Chen F, 2014 b. Numerical simulations of boundary-layer processes and urban-induced alterations in an Alpine valley. Int. J. Climatol. 34:1111-1131.

Goudsmit GH, Burchard H, Peeters F, Wüest A, 2002. Application of $\mathrm{k}-\varepsilon$ turbulence models to enclosed basins: The role of internal seiches. J. Geophys. Res. 107:3230-3230.

Goyette S, Perroud M, 2012. Interfacing a one-dimensional lake model with a single-column atmospheric model: Application to the deep Lake Geneva, Switzerland. Water Resour. Res. 48:4507.

Heaps NS, 1984. Vertical structure of current in homogeneous and stratified waters, p. 153-207. In: K. Hutter (ed.), Hydrodynamics of lakes: CISM lectures. Springer Verlag.

Henderson-Sellers B, 1988. The dependence of surface velocity in water bodies on wind velocity and latitude. Appl. Math. Model. 12:202-203.

Hodges BR, Imberger J, Saggio A, Winters KB, 2000. Modeling basin-scale internal waves in a stratified lake. Limnol. Oceanogr. 45:1603-1620.

Hostetler SW, Bates G, Giorgi F, 1993. Interactive coupling of a lake thermal model with a regional climate model. J. Geophys. Res. 98:5045-5057.

Hutter K, Wang Y, Chubarenko IP, 2011. Physics of Lakes. 1. Foundation of the Mathematical and Physical Background. Springer.

Huziy O, Sushama L, 2017. Lake-river and lake-atmosphere interactions in a changing climate over Northeast Canada. Clim. Dynam. 48:3227-3246.

IRSA, 1974. Research on Lake Garda. IRSA, Quaderni.

Kelley JGW, Hobgood JS, Bedford KW, Schwab DJ, 1993. Generation of three-dimensional lake model forecasts for Lake Erie. Weather Forecast. 13:305-315.

Laiti L, Zardi D, De Franceschi M, Rampanelli G, 2013a. 
Atmospheric boundary-layer structures associated with the Ora del Garda wind in the Alps as revealed from airborne and surface measurements. Atmos. Res. 132:473-489.

Laiti L, Zardi D, De Franceschi M, Rampanelli G, 2013b. Residual Kriging analysis of airborne measurements: application to the mapping of Atmospheric Boundary-Layer thermal structures in a mountain valley. Atmos. Sci. Lett. 14:79-85.

Laiti L, Zardi D, De Franceschi M, Rampanelli G, Giovannini L, 2014. Analysis of the diurnal development of a lakevalley circulation in the Alps based on airborne and surface measurements. Atmos. Chem. Phys. 14:9771-9786.

Laval B, Imberger J, Hodges BR, Stocker R, 2003. Modeling circulation in lakes: Spatial and temporal variations. Limnol. Oceanogr. 48:983-994.

Laval BE, Imberger J, Findikakis AN, 2005. Dynamics of a large tropical lake: Lake Maracaibo. Aquat. Sci. 67:337-349.

Lemmin U, D'adamo N, 1996. Summertime winds and direct cyclonic circulation:observations from Lake Geneva. Ann. Geophysicae 14:1207-1220.

Leon LF, Lamb DCL, Schertzer WM, Swayne DA, Imberger J, 2007. Towards coupling a 3D hydrodynamic lake model with the Canadian Regional Climate Model: Simulation on Great Slave Lake. Environ. Model. Software 22:787-796.

Lesser GR, Roelvink JA, Keste TMV, Stelling GS, 2004. Development and validation of a three-dimensional morphological model. Coast. Eng. 51:883-915.

Monismith NG, Macintyre S, 2010. The surface mixed layer in lakes and reservoirs, p. 207-221. in: G. E. Likens (ed.), Biogeochemistry of inland waters. Elsevier, San Diego.

Notaro M, Holman K, Zarrin A, Fluck E, Vavrus S, Bennington $\mathrm{V}, 2013$. Influence of the Laurentian Great Lakes on regional climate. J. Climate 26:789-804.

Pan H, Avissar R, Haidvoge DB, 2002. Summer circulation and temperature structure of Lake Kinneret. J. Phys. Ocean. 32:295-313.

Perroud M, Goyette S, Martynov A, Beninston M, Anneville O, 2009. Simulation of multiannual thermal profiles in deep Lake Geneva: A comparison of one-dimensional lake models. Limnol. Oceanogr. 54:1574-1594.

Piccolroaz S, Toffolon M, 2013. Deep water renewal in Lake Baikal: a model for long term analyses. J. Geophys. Res. 118:6717-6733.

Piccolroaz S, Toffolon M, 2018. The fate of Lake Baikal: how climate change may alter deep ventilation in the largest lake on Earth. Climatic Change 150:181-194.

Rao YR, Murthy CR, 2001. Coastal boundary layer characteristics during summer stratification in Lake Ontario. J. Phys. Oceanogr. 31:1088-1104.

Rao YR, Schwab DJ, 2007. Transport and mixing between the coastal and offshore waters in the Great Lakes: a review. J. Great Lakes Res. 33:202-218.

Razmi AM, Barry DA, Bakhtyar R, Wüest A, 2013. Current variability in a wide and open lacustrine embayment in Lake Geneva (Switzerland). J. Great Lakes Res. 39:455-465.

Razmi AM, Barry DA, Lemmin U, Bonvin F, Kohn T, Bakhtyar $\mathrm{R}, 2014$. Direct effects of dominant winds on residence and travel times in the wide and open lacustrine embayment: Vidy Bay (Lake Geneva, Switzerland). Aquat. Sci. 76:S59-S71.

Razmi AM, Lemmin U, Bouffard D, Wüest A, Uittenbogaard RE, Barry DA, 2017. Gyre formation in open and deep lacustrine embayments: the example of Lake
Geneva, Switzerland. Environ. Fluid Mech. 17:415-428.

Rueda FJ, Schladow SG, Monismith SG, Stacey MT, 2005. On the effects of topography on wind and the generation of currents in a large multi-basin lake. Hydrobiologia 532: 139-151.

Santo M, Toffolon M, Zanier G, Giovannini L, Armenio V, 2017. Large Eddy Simulation (LES) of wind-driven circulation in a peri-alpine lake: detection of turbulent structures and implications of a complex surrounding orography. J. Geophys. Res. 122:4704-4722.

Schimmelpfenning S, Kirillin G, Engelhardt C, Nützmann G, 2012. Effects of wind-driven circulation on river intrusion in Lake Tegel: modeling study with projection on transport of pollutants. Environ. Fluid Mech. 12:321-339.

Schwab DJ, Clites AH, Murthy CR, Sandall JE, Meadows LA, Meadows GA, 1989. The effect of Wind on Transport and Circulation in Lake St. Clair. J. Geophys. Res. 94:4947-4958.

Serafin S, Adler B, Cuxart J, De Wekker SFJ, Gohm A, Grisogono B, Kalthoff N, Kirshbaum DJ, Rotach MW, Schmidli J, Stiperki I, Vecenaj E-, Zardi D, 2018. Exchange processes in the atmospheric boundary layer over mountainous terrain. Atmosphere 9:102.

Skamarock WC, Klemp JB, Dudhia J, Gill DO, Barker DM, G.Duda M, Huang XY, Wang W, Powers JG, 2008. A description of the advanced research WRF version 3. NCAR Technical Note TN-475+STR, 125.

Song Y, Semazzi FHM, Xie L, Ogallo LJ, 2004. A coupled regional climate model for the Lake Victoria basin of East Africa. Int. J. Climatol. 24:57-75.

Stocker R, Imberger J, 2003. Horizontal transport and dispersion in the surface layer of a medium sized lake. Limnol. Oceanogr. 48:971-982.

Strub PT, Powell TM, 1986. Wind-driven surface transport in stratified closed basins: Direct versus residual circulations. J. Geophys. Res. 91:8497-8508.

Toffolon M, 2013. Ekman circulation and downwelling in narrow lakes. Adv. Water Resour. 53:76-86.

Toffolon M, Piccolroaz S, Dijkstra HA, 2017. A plunge into the depths of Italy's Lake Garda. Eos 98. DOI: https://doi.org/10.1029/2017EO074499

Umlauf L, Lemmin U, 2005. Interbasin exchange and mixing in the hypolimnion of a large lake: The role of long internal waves. Limnol. Oceanogr. 50:1601-1611.

Valerio G, Cantelli A, Monti P, Leuzzi G, 2017. A modeling approach to identify the effective forcing exerted by wind on a prealpine lake surrounded by a complex topography. Water Resour. Res. 53:4036-4052.

Wahl B, Peeters F, 2014. Effect of climatic changes on stratification and deep-water renewal in Lake Constance assessed by sensitivity studies with a $3 \mathrm{D}$ hydrodynamic model. Limnol. Oceanogr. 59:1035-1052.

Wang Y, Hutter K, Bäuerle E, 2000. Wind-induced baroclinic response of Lake Constance. Ann. Geoph. 18:1488-14501.

Xue P, Pal JS, Ye X, Lenters JD, Huang C, Chu PY, 2016. Improving the simulation of large lakes in regional climate modeling: Two-way lake-atmosphere coupling with a 3-D hydrodynamic model of the Great Lakes. J. Climate 30:1605-1627.

Zhong Y, Notaro M, Vavrus SJ, Foster MJ, 2016. Recent accelerated warming of the Laurentian Great Lakes: Physical drivers. Limnol. Oceanogr. 61:1762-1786. 